\title{
Two new species of cricket frogs of the genus Fejervarya Bolkay, 1915 (Anura: Dicroglossidae) from the Peninsular India
}

\author{
Prudhvi Raj ${ }^{1}$, K. P. Dinesh², Abhijit Das ${ }^{1}$, Sushil K. Dutta ${ }^{3}$, Niladri B. Kar ${ }^{4}$ and Pratyush P. Mohapatra5* \\ 'Wildlife Institute of India, Chandrabani, Dehradun - 248001, Uttarakhand, India \\ 2Zoological Survey of India, Western Regional Centre, Pune - 411044, Maharashtra, India \\ ${ }^{3}$ Nature Environment and Wildlife Society, Angul, Odisha - 759122, India \\ ${ }^{4}$ P. G. Department of Zoology, North Orissa University, Baripada - 757003, Odisha, India \\ ${ }^{5}$ Zoological Survey of India, Central Zone Regional Centre, Jabalpur - 482002, \\ Madhya Pradesh, India; pratyushm.zsi@gmail.com
}

\begin{abstract}
The Dicroglossidae frogs of genus Fejervarya Bolkay, 1915 are morphologically cryptic and represented by one of the widespread group of frogs across the tropical Asia comprising about 45 species. Being morphologically cryptic, taxonomic status for many of the species remains uncertain. Recent studies using integrative taxonomic approach have revealed the existence of many novel and hitherto undescribed species. Herewith, we describe two new species of Fejervarya viz. Fejervarya kalinga sp. nov. and Fejervarya krishnan sp. nov. from peninsular India having morphological and phylogenetic distinctness. Detailed morphological descriptions and comparisons with the known congeners along with their systematic relationship inferred from phylogenetic analyses are presented herein. Taxonomic problems within the genus for the peninsular India and the pattern of phylogenetic relationships are also presented.
\end{abstract}

Keywords: Cryptic Species, Eastern Ghats, Fejervarya, India, New Species, Phylogeny, South Asia, Western Ghats

\section{Introduction}

The Asian cricket frogs of genus Fejervarya Bolkay, 1915 is one of the speciose groups in the anuran family Dicroglossidae (Dubois, 1975; Das and Dutta, 1998) and currently consists of 45 species distributed in South and South East Asia (Frost, 2018). Members of this genus can be diagnosed from the rest of Dicroglossid frogs by presence of fejervaryan lines on both sides on the ventrolateral sides. These frogs are generally small to medium sized, semi-aquatic in habit and mostly live near the edge of ponds, marshes, rivers, forest streams and paddy fields. Being cryptic, mainly because of the conserved external morphological attributes (Dubois, 1987; Toda et al. 1998; Chanda, 2002; Daniels, 2005; Kuramoto et al., 2007;
Garg and Biju, 2017), these frogs are generally difficult to identify based on only morphological characters and hence, identification of this group currently aided by acoustic as well as genetic analysis (Dutta and Manamendra-Arachchi, 1996; Dutta and Singh, 1996; Matsui et al., 2007). Genetic studies on this group have revealed that some morphologically defined species in this group are actually species complexes (Sumida et al., 2002; Kurabayashi et al., 2005; Djong et al., 2007; Matsui et al., 2007; Sumida et al., 2007; Islam et al., 2008; Meenakshi et al., 2010; Hasan et al., 2012; Garg and Biju, 2017). Hence, the systematics of these frogs has undergone many revisions in the last few years (Fei et al., 2002; Frost et al., 2006; Howlader, 2011; Ohler et al., 2014; Dinesh et al., 2015).

\section{* Author for correspondence}


The Peninsular India harbors a unique and diverse amphibian fauna. In recent years, many new species have been described from this region having bio-geographic and conservation significance (Daniels, 1992; Dubois, 1999; Bossuyt and Milinkovitch, 2000; Biju and Bossuyt, 2003; Dutta et al., 2004; Van Bocxlaer et al., 2006). The Indian sub-continent is represented by 29 species of Fejervarya (Dinesh et al., 2017; Frost, 2018) of which the type localities for four species viz., $F$. cancrivora, $F$. nepalensis, $F$. pierrei and F. teraiensis fall outside the political boundaries of India though their range extends into the mainland of India. Among the rest, 25 species that are described from India, type localities of two species are from Northeast India (F. chilapata and F. sengupti); two species from Indian Islands ( $F$. andamanensis and F. nicobariensis); 20 species from Western Ghats (F. brevipalmata, F. caperata, F. cepfi, F. gomantaki, F. granosa, F. kadar, F. keralensis, F. kudremukhensis, F. manoharani, F. modesta, F. mudduraja, F. murthii, F. mysorensis, F. neilcoxi, F. nilagirica, F. parambikulamana, F. rufescens, F. sahyadris, F. sauriceps and F. syhadrensis) and one species from Eastern Ghats (F. orissaensis). Further, among the Fejervarya frogs described from India there are taxonomic issues like, erroneous type locality data (e.g., F. brevipalmata) and missing or loss of the type specimens (e.g. F. modesta, F. parambikulamana and F. sauriceps) (Frost, 2018). Also for two species viz. F. murthii and F. mysorensis, there is no further record apart from type collections (Frost, 2018).

During our recent field surveys in the Eastern Ghats and the Western Ghats of Peninsular India, we encountered several individuals which are assignable to the genus Fejervarya based on the diagnosable generic morphological characters assigned by Bolkay, 1915 for the genus (Dinesh et al., 2015) and those did not match the descriptions of any extant taxon of the group. Phylogenetic analysis confirmed our generic allocation and availability of two new taxa. Herewith, we describe two new species, one each from the Eastern and the Western Ghats having morphological and genetic distinctness from each other as well as from other members of this group.

\section{Materials and Methods}

The field study was conducted during 2015 and 2016 (Figure 1 shows sampled localities). Specimens were euthanized and fixed in $10 \%$ buffered formalin for 24 hours before preserving in $70 \%$ ethanol. Details of the habitat along with natural history notes of the collected specimens were recorded onsite. Live photographs were taken within 30 minutes of collection of the samples and the fixed specimen photographs were taken in the laboratory before depositing in the museum. Specimens are deposited in the national zoological collection of Zoological Survey of India, Western Ghats Regional Centre, Pune and in the Vertebrate museum at Wildlife Institute of India (WII). For molecular analysis, muscle tissue samples from thigh region were collected in 100\% ethanol (Merck, Germany). DNA was extracted from the tissue samples, using DNeasy blood and tissue kit (Qiagen, Germany) following manufacturer's protocol. PCR was carried out for $16 \mathrm{~S}$ and $12 \mathrm{~S}$ rRNA genes. The $16 \mathrm{~S}$ rRNA was amplified using the forward primer 16Sar-L: 5'-GCCTGTTTATCAAAAACAT-3' and reverse primer 16Sbr-H: 5'CCGGTCTGAACTCAGATCACGT-3') (Palumbi et al., 1991). Similarly the 12S rRNA was amplified using the forward primer FS01 5' - ACGCTAAGATGAACCCTAAAAAGTTCT-3' and reverse primer R16M1: 5'-GGGTATCTAATCCC

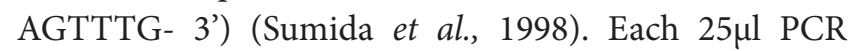
amplification mixture composed of $2.5 \mu \mathrm{l} \mathrm{MgCl}_{2}, 2.5$ $\mu \mathrm{l}$ PCR buffer, $2.5 \mu \mathrm{l}$ of dNTPs, $0.25 \mu \mathrm{l}$ of each primer (forward and reverse), $1 \mu$ l of purified DNA, $0.67 \mu$ l of Taq polymerase (Bangalore Genei Pvt. Ltd.), and rest Milli-Q water. The target regions were amplified using the PCR profile comprising an initial hot start at $94^{\circ} \mathrm{C}$ (4 min), followed by 40 cycles of $94^{\circ} \mathrm{C}$ denaturation ( 45 sec), $47.1^{\circ} \mathrm{C}$ annealing $(1 \mathrm{~min})$ and $72^{\circ} \mathrm{C}$ extension $(1$ $\mathrm{min}$ ), and a final extension at $72^{\circ} \mathrm{C}$ for $10 \mathrm{~min}$. The PCR products generated were purified using spin columns and then sequenced using 3130xl Genetic Analyzer.

For phylogenetic reconstruction, $16 \mathrm{~S}$ rRNA and $12 \mathrm{~S}$ rRNA sequences from Dinesh et al., 2015, Dahanukar et al., 2017 and Garg and Biju (2017) along with the two undescribed Fejevraya sp. phylogenies were constructed using maximum likelihood, as implemented in RAxML v. 8. (Stamatakis, 2014). The RAxML v. 8 uses only the GTR model (general time reversible), and so analyses of model fitting were not performed, given that all other substitution models represent special cases of GTR. A parameter for variation in rates among sites $(\Gamma)$ along with invariant sites parameter was also included $(\mathrm{GTR}+\mathrm{G}+\mathrm{I})$. To find the optimal likelihood tree, 250 independent tree searches on the partitioned data were performed. The support for 
individual branches was evaluated using nonparametric bootstrapping using 1000 bootstrap replicates. The dataset included sequences from Fejeravarya sp. from south and South East Asia and Occidozyga was used as the out-group following Dinesh et al. (2015).

Uncorrected pair-wise genetic distances (p-distances) were computed in MEGA v.6 to delineate species from their congeneric sister taxon using 16s rRNA gene data (Vences et al. 2005). For lineage diagnosis, multiple criteria were used like phylogeny, genetic distance, geographic isolation and morphological characters following Vijayakumar et al., (2014) and Dinesh et al. (2015).

Morphological measurements are taken using a SPI Polymid Dial Caliper to the nearest $0.1 \mathrm{~mm}$ and minute morphological characters were observed under LEICA
EZ4 Stereo-Zoom microscope (Table 1 and 2). Principal Component Analysis (PCA) was performed in PAST version 3.18 (Hammer et al., 2001). We used allometric ratios of eight and eighteen morphometric variables for larger and smaller Fejervarya species respectively from the published data provided in Dutta (1997), Ohler et al., (2009) and Dinesh et al. (2015) (Table 3 and 4). The web formula followed is after Myers and Duellman (1982).

\section{Abbreviations}

SVL, Snout-Vent Length (from tip of snout to vent); SL, Snout Length (from the anterior corner of eye to snout tip); EN, Eye to Nostril distance (distance between anterior most point of eyes and nostrils); NS, Nostril to Snout distance (distance between anterior most point of nostril to snout tip); INS, Inter-Narial Space (distance

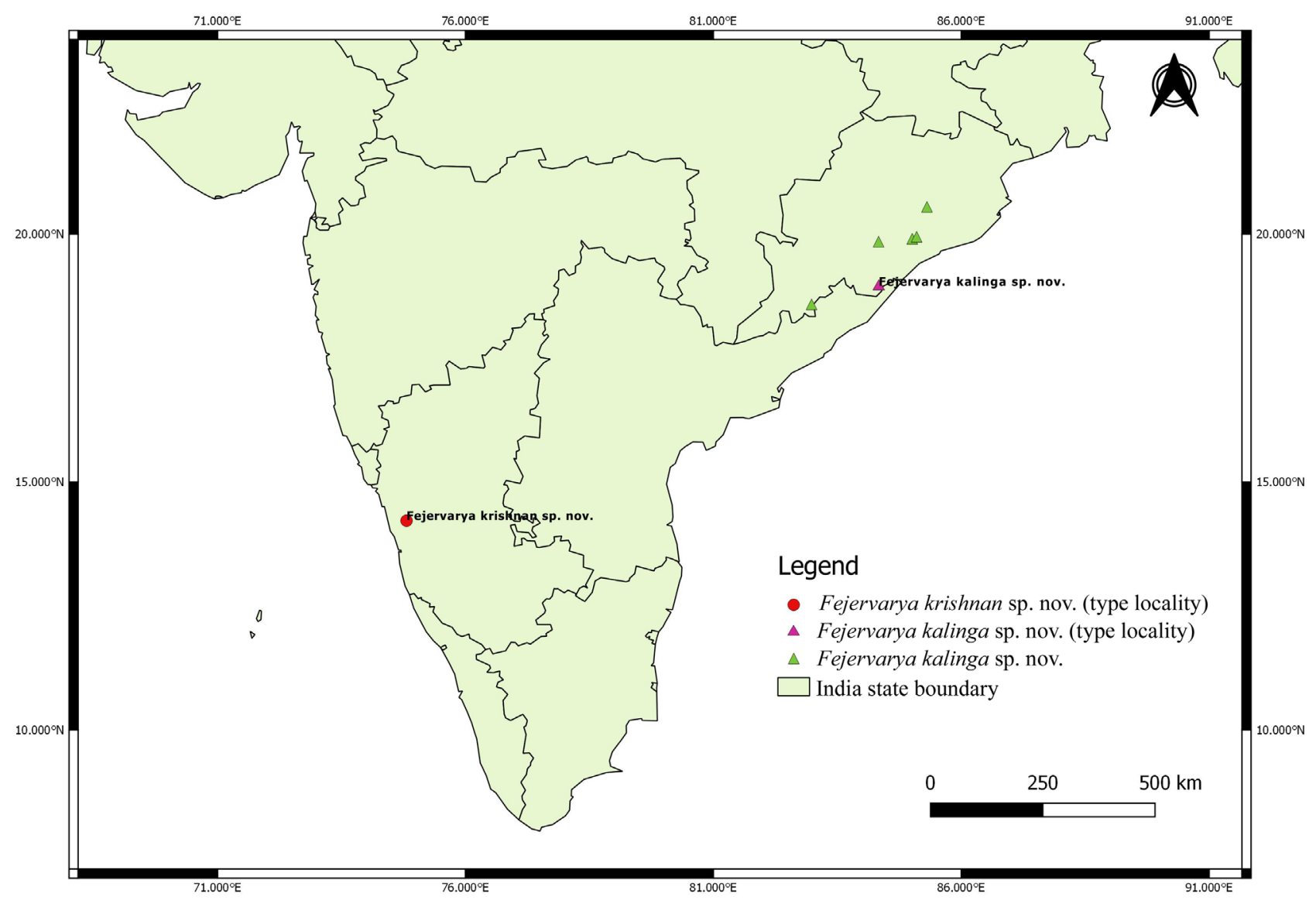

Figure 1. Map showing distribution of Fejervarya kalinga sp. nov. (in triangles, type locality in purple) and Fejervarya krishnan sp. nov. (in circle). 
between nostrils); IOS, Inter-Orbital Space (least distance between upper eyelids); TE, Tympanum to posterior corner of Eye distance; UE Upper Eyelid width; ED, eye diameter (horizontal diameter of the eyes); HL, Head Length (distance between angle of jaws and snout-tip); HWN, Head Width at Nostrils; HWAE, Head Width at the Anterior Corner of Eye (width of head at the level of anterior corner of eye); HWPE, Head Width at the Posterior Corner of Eye (width of the head at the level of posterior corner of eye); HWAJ, head width at angle of jaw (width of head at the level of jaw angle); HTYD, Horizontal Tympanic Diameter (greatest tympanum diameter along horizontal plane); VTYD, Vertical Tympanic Diameter (greatest tympanum diameter along vertical plane;) MN, Mandible to Nostril (distance from posterior corner of the mandible to the nostril); MAE, Mandible to Anterior part of Eye (distance from posterior corner of the mandible to the anterior corner of the eye); MPE, Mandible to Posterior part of Eye (distance from posterior corner of the mandible to the posterior corner of the eye); IAE, distance between anterior corner of eye; IPE, distance between posterior corner of eye; FaL, Forearm Length; HaL, Hand Length; F1 to F4, length of 1 st to 4 th fingers (from the base to the tip of the respective finger); AG, forearm pit to groin length; TBL, Tibia Length (distance between surface of knee and surface of heel, with both tibia and tarsus flexed); TBW, Tibia Width (maximum width of tibia along its length); TiL, Thigh Length; TL, Tarsal Length; FtL, Foot Length; T1 to T5, individual length of all toes (from proximal end of inner metatarsal tubercle to the tip of the respective toe); WII, Wildlife Institute of India; ZSI, Zoological Survey of India.

\section{Results}

\section{Systematic Accounts}

Both the new species is assignable to the genus Fejervarya Bolkay, 1915 based on the morphological characters and phylogenetic position within the 'Fejervarya clade' (Dinesh et al., 2015) (Figure 2).

\section{Species Description}

Fejervarya kalinga sp. nov.

(Table 1 and 3; Refer Figures 1, 2, 3, 4 and 5)
Materials examined: Holotype: Adult male: India, Odisha, Mahendragiri, Gajapati District (N 18.94162 E $84.33361^{\circ}$ ), altitude $1210 \mathrm{~m} \mathrm{ASL,} \mathrm{15-VI-2016,} \mathrm{coll.} \mathrm{S.K.}$ Dutta and P.P. Mohaptra (Regd. No. ZSI/WRC/A/2018).

Paratypes: Two males and two females. Male: India, Odisha, Khordha district, Barbara Reserve Forest (RF), Mahulia, (N19.88692 ${ }^{\circ}$, E85.00944), Alt 728m ASL, coll. S.K. Dutta and P.P. Mohapatra, (ZSI/WRC/A/2019); Male: India, Odisha, Dhenkanal district, Hindol, Rajanga forest, (N20.53103, E85.30583), Alt 626m ASL, coll. S.K. Dutta, (ZSI/WRC/A/2020); Female, India, Andhra Pradesh, Visakhapatnam district, Sileru, (N18.0482 ${ }^{\circ}$ E82.0339 $)$, Alt. 1196m ASL, coll. Prudhvi Raj, (ZSI/WRC/A/2021); and Female, India, Odisha, Gajapati district, Mahendragiri, $\left(\mathrm{N} 18.94162^{\circ}, \mathrm{E} 84.33361^{\circ}\right)$, Alt. 1210m ASL, coll. S.K. Dutta and P.P. Mohapatra (ZSI/WRC/2022).

Lineage diagnosis (Figure 2): Fejervarya kalinga sp. nov. can be diagnosed phylogenetically as a member of the fejervaryan clade, showing a sister relationship to $F$. keralensis, exhibiting high level of genetic divergence of $7 \%$ for $16 \mathrm{~S}$ rRNA. Morphologically males of the new species can be distinguished from $F$. keralensis in having relatively larger SVL $(40.4 \mathrm{~mm} \pm 2.81 \mathrm{~mm}, \mathrm{n}=4)$ (vs. relatively smaller SVL $37.5 \mathrm{~mm} \pm 3.36, \mathrm{n}=5 \mathrm{in}$ F. keralensis); greater HL/SVL ratio of 0.373 (0.354 to $0.401, \mathrm{n}=4)$ (vs. smaller HL/SVL ratio of $0.306, \mathrm{n}=5$ in F. keralensis); greater ED/SVL ratio of 0.149 ( 0.144 to $0.155, \mathrm{n}=4$ ) (vs. lesser $\mathrm{ED} / \mathrm{SVL}$ ratio of $0.122, \mathrm{n}=5$ in $F$. keralensis); higher IOS/SVL ratio of 0.078 (0.071 to $0.089, \mathrm{n}=4$ ) (vs. lower IOS/SVL ratio $0.061, \mathrm{n}=5$ in F. keralensis); higher $\mathrm{ThL} /$ SVL ratio of 0.523 ( 0.484 to $0.579, \mathrm{n}=4$ ) (vs. lower ThL/ SVL ratio of $0.474, \mathrm{n}=5$ in F. keralensis). The adult females of Fejervarya kalinga sp. nov. have relatively larger SVL $54.5 \mathrm{~mm} \pm 5.46, \mathrm{n}=6$ (vs. relatively smaller SVL $48.9 \mathrm{~mm}$ $\pm 7.58 \mathrm{~mm}, \mathrm{n}=5$ in F. keralensis); greater HL/SVL ratio of $0.356(0.356$ to $0.379, \mathrm{n}=6$ ) (vs. lower HL/SVL ratio of $0.319, \mathrm{n}=5$ in F. keralensis); a lower INS/SVL ratio of 0.077 ( 0.068 to $0.088, \mathrm{n}=6$ ) (vs. higher INS/SVL ratio $0.089, \mathrm{n}=5$ in F. keralensis); greater ED/SVL ratio of 0.122 (0.114 to $0.132, \mathrm{n}=6$ ) (vs. lower ED /SVL ratio of $0.110, \mathrm{n}=5$ in $F$. keralensis).

Morphological diagnosis: In the field, Fejervarya kalinga sp. nov. can be identified based on the combination of 


\begin{tabular}{|c|c|c|c|c|c|c|c|c|c|c|c|c|c|c|c|c|c|c|c|}
\hline 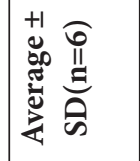 & & 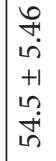 & 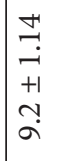 & $\begin{array}{l}10 \\
0 \\
0 \\
+1 \\
\infty \\
10\end{array}$ & \begin{tabular}{l}
2 \\
mे \\
0 \\
+1 \\
\multirow{r}{+}{}
\end{tabular} & $\begin{array}{l}0 \\
0 \\
0 \\
+1 \\
0 \\
m\end{array}$ & 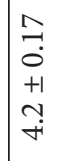 & \begin{tabular}{l}
\multirow{H}{*}{} \\
0 \\
0 \\
+1 \\
0 \\
$\dot{n}$
\end{tabular} & $\begin{array}{l}m \\
3 \\
0 \\
+1 \\
0 \\
+ \\
+\end{array}$ & $\begin{array}{l}\infty \\
m \\
0 \\
+1 \\
+1 \\
0 \\
0\end{array}$ & $\begin{array}{l}0 \\
n \\
0 \\
+1 \\
+1 \\
0 \\
+ \\
+\end{array}$ & $\begin{array}{l}m \\
m \\
0 \\
+1 \\
\sim \\
+ \\
+\end{array}$ & $\mid \begin{array}{l}2 \\
2 \\
+1 \\
+1 \\
+1 \\
2 \\
-1\end{array}$ & 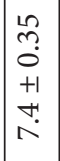 & 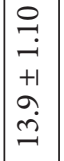 & 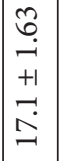 & 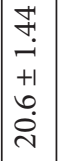 & 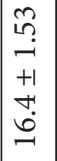 & 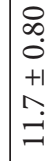 \\
\hline 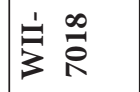 & I & $\overrightarrow{\text { ñ }}$ & $\begin{array}{l}0 \\
\infty\end{array}$ & $\begin{array}{l}0 \\
i \stackrel{0}{ }\end{array}$ & F & $\stackrel{0}{\dot{m}}$ & $F$ & $\ddot{m}$ & $\stackrel{H}{+}$ & $\hat{6}$ & $\stackrel{m}{+}$ & $\vec{F}$ & \begin{tabular}{|l|}
0 \\
$\infty$ \\
$\infty$ \\
$-\infty$
\end{tabular} & $\stackrel{2}{i}$ & 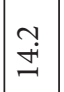 & $\stackrel{\sim}{\stackrel{2}{*}}$ & 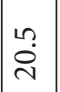 & 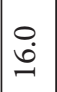 & 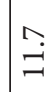 \\
\hline$\frac{1}{3} \frac{1}{2}$ & L & $\vec{q}$ & $\infty$ & i. & I & $\stackrel{\infty}{i}$ & $\stackrel{m}{+}$ & $\stackrel{n}{n}$ & $\stackrel{\overrightarrow{+}}{+}$ & $\begin{array}{l}10 \\
6\end{array}$ & $\stackrel{b}{+}$ & $\stackrel{\circ}{\rightarrow}$ & $\mid \begin{array}{l}6 \\
\infty \\
0 \\
-1\end{array}$ & જે & $\stackrel{\Im}{\exists}$ & $\mid \begin{array}{l}0 \\
\text { in } \\
-1\end{array}$ & $\begin{array}{l}\stackrel{\infty}{\infty} \\
\infty\end{array}$ & $\begin{array}{l}n \\
\stackrel{n}{-2} \\
n\end{array}$ & $\stackrel{+}{\Xi}$ \\
\hline$\frac{1}{3} \frac{n}{2}$ & L & $\begin{array}{l}0 \\
\dot{1}\end{array}$ & $\stackrel{6}{=}$ & $\stackrel{?}{\sim}$ & 望 & $\stackrel{\circ}{\dot{r}}$ & $\stackrel{+}{+}$ & $\stackrel{\circ}{+}$ & ir. & $\stackrel{2}{\Lambda}$ & in & $\stackrel{g}{+}$ & $\begin{array}{l}\ddot{0} \\
\ddot{\sim}\end{array}$ & $\stackrel{\Upsilon}{\curvearrowright}$ & $\begin{array}{l}m \\
\stackrel{n}{n} \\
n\end{array}$ & $\stackrel{0}{\dot{i}}$ & $\stackrel{\sim}{\tilde{n}}$ & $\stackrel{+}{a}$ & $\vec{m}$ \\
\hline$\stackrel{3}{3}$ & I & $\frac{9}{\sin }$ & $\stackrel{\partial}{\infty}$ & in & $\stackrel{n}{+}$ & $\hat{i}$ & $\stackrel{0}{\rightarrow}$ & $\stackrel{m}{n}$ & $\stackrel{\ln }{\rightarrow}$ & 0 & $\stackrel{\leftrightarrow H}{+}$ & $\vec{F}$ & $\mid \begin{array}{l}10 \\
\infty \\
-1\end{array}$ & $\stackrel{\Upsilon}{N}$ & $\stackrel{\circ}{ \pm}$ & ఫે & $\ddot{i}$ & $\begin{array}{l}\stackrel{2}{n} \\
\text { மे }\end{array}$ & $\hat{\varrho}$ \\
\hline 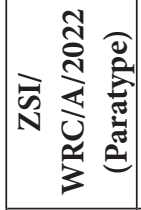 & I & $\begin{array}{l}0 \\
\text { in }\end{array}$ & $\stackrel{\circ}{\circ}$ & in & r & $\dot{m}$ & $\stackrel{\circ}{\rightarrow}$ & $\stackrel{n}{m}$ & $\underset{+}{\sigma}$ & تే & $\stackrel{\leftrightarrow}{+}$ & $\stackrel{\text { I }}{+}$ & $\begin{array}{l}\stackrel{\rho}{\infty} \\
\infty \\
-1\end{array}$ & $\stackrel{\bullet}{\sim}$ & $\stackrel{\circ}{\underset{+}{+}}$ & $\vec{\triangle}$ & $\ddot{i}$ & $\begin{array}{l}\stackrel{+!}{0} \\
\stackrel{\text { L }}{n}\end{array}$ & $\stackrel{\circ}{=}$ \\
\hline 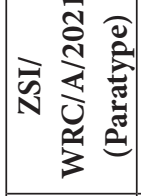 & 山 & $\stackrel{n}{n}$ & $\stackrel{\sigma_{0}}{\infty}$ & in & $\underset{+}{\stackrel{0}{+}}$ & $\vec{m}$ & $\stackrel{m}{+}$ & $\stackrel{\varphi}{\dot{m}}$ & $\stackrel{m}{+}$ & تే & $\stackrel{\leftrightarrow}{+}$ & $\underset{+}{\vec{P}}$ & $\left|\begin{array}{l}1 \\
\infty \\
\infty \\
-1\end{array}\right|$ & $\stackrel{n}{n}$ & $\stackrel{0}{ \pm}$ & $\mid$ & $\hat{\tilde{i}}$ & 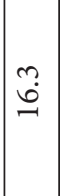 & $\stackrel{\infty}{=}$ \\
\hline 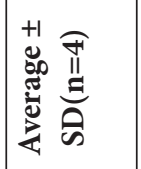 & & $\begin{array}{l}\infty \\
\infty \\
i \\
+1 \\
+1 \\
0 \\
0 \\
+\end{array}$ & $\begin{array}{l}0 \\
n \\
0 \\
+1 \\
+! \\
n\end{array}$ & $\begin{array}{l}0 \\
0 \\
0 \\
+1 \\
\sim \\
+1\end{array}$ & $\begin{array}{l}1 \\
\dot{0} \\
+1 \\
0 \\
\dot{m}\end{array}$ & $\begin{array}{l}0 \\
0 \\
0 \\
+1 \\
0 \\
0 \\
-1\end{array}$ & $\begin{array}{l}+1 \\
0 \\
0 \\
+1 \\
10 \\
n\end{array}$ & 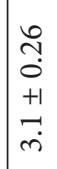 & $\begin{array}{l}\infty \\
\stackrel{0}{0} \\
0 \\
+1 \\
\dot{n} \\
\dot{n}\end{array}$ & $\begin{array}{l}0 \\
10 \\
0 \\
+1 \\
0 \\
0 \\
0\end{array}$ & $\begin{array}{c}1 \\
0 \\
0 \\
+1 \\
0 \\
\dot{n} \\
0\end{array}$ & $\begin{array}{c}0 \\
\infty \\
0 \\
+1 \\
+1 \\
m \\
n \\
n\end{array}$ & 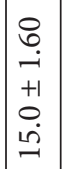 & $\mid \begin{array}{c}\infty \\
\tilde{m} \\
0 \\
+1 \\
\tilde{n} \\
\tilde{0}\end{array}$ & $\mid \begin{array}{c}\infty \\
0 \\
0 \\
0 \\
+1 \\
+1 \\
0 \\
0 \\
-1\end{array}$ & $\mid \begin{array}{c}\hat{a} \\
\hat{0} \\
+1 \\
\hat{\jmath} \\
\end{array}$ & 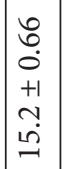 & 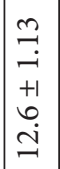 & $\begin{array}{l}0 \\
0 \\
0 \\
+1 \\
-1 \\
a\end{array}$ \\
\hline 商 & $\Sigma$ & 亩 & $\stackrel{0}{\circ}$ & $\stackrel{\sim}{+}$ & $\stackrel{H}{m}$ & $\cong$ & $\stackrel{m}{n}$ & $\hat{i}$ & $\hat{m}$ & $\begin{array}{l}10 \\
\text { in }\end{array}$ & $\stackrel{H}{m}$ & $\dot{m}$ & $\stackrel{\circ}{+}$ & $\begin{array}{l}\hat{i n} \\
\text { in }\end{array}$ & $\stackrel{0}{0}$ & $\stackrel{\dot{m}}{\dot{m}}$ & 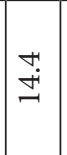 & $\stackrel{9}{=}$ & $\stackrel{\circ}{a}$ \\
\hline 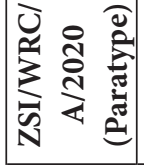 & $\Sigma$ & $\stackrel{n}{\dot{m}}$ & $\stackrel{?}{\wedge}$ & $\stackrel{\sim}{+}$ & $\stackrel{\dot{m}}{\dot{m}}$ & $\stackrel{0}{-}$ & $\stackrel{b}{\dot{m}}$ & $\stackrel{\stackrel{n}{m}}{m}$ & $\stackrel{\infty}{\infty}$ & in & $\ddot{m}$ & $\hat{\mathrm{i}}$ & $\underset{\dot{+}}{+}$ & 官 & $\stackrel{2}{2}$ & İ & $\mid$\begin{tabular}{l}
$n$ \\
\hdashline \\
\hdashline
\end{tabular} & 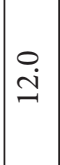 & $\begin{array}{l}n \\
\infty \\
\infty\end{array}$ \\
\hline 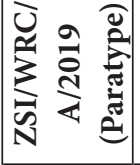 & $\Sigma$ & 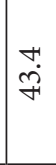 & $\stackrel{a}{\Lambda}$ & $\stackrel{+}{+}$ & $\stackrel{\infty}{r}$ & $\stackrel{n}{\longrightarrow}$ & $\dot{\vec{r}}$ & $\vec{r}$ & $\bar{F}$ & $\overrightarrow{6}$ & $\vec{F}$ & $\stackrel{\infty}{m}$ & $\stackrel{+!}{\stackrel{2}{\beth}}$ & $\stackrel{\bullet}{6}$ & $\stackrel{\varrho}{0}$ & $\nexists$ & 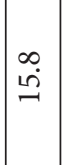 & $\stackrel{m}{\ddot{+}}$ & $\stackrel{\circ}{\circ}$ \\
\hline 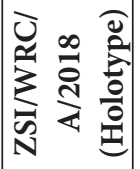 & $\Sigma$ & $\stackrel{g}{\vec{j}}$ & $\stackrel{?}{\sim}$ & $\stackrel{m}{+}$ & $\stackrel{0}{\dot{m}}$ & ن. & $\stackrel{n}{n}$ & $\stackrel{0}{\dot{m}}$ & $\underset{+}{\circ}$ & $\begin{array}{l}10 \\
6\end{array}$ & $\stackrel{\circ}{\rightarrow}$ & $\stackrel{\infty}{\infty}$ & $\begin{array}{l}0 \\
\text { in } \\
\end{array}$ & 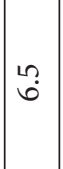 & $\stackrel{\circ}{\circ}$ & 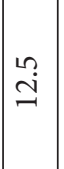 & $\begin{array}{l}0 \\
\stackrel{0}{0} \\
\text { in } \\
-1\end{array}$ & 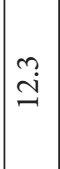 & $\stackrel{\circ}{\circ}$ \\
\hline $\begin{array}{l}\dot{0} \\
\dot{z} \\
\dot{\ddot{z}}\end{array}$ & 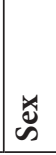 & 空 & क & Z工工 & $\tilde{z}$ & 牙 & $\tilde{Z}$ & $\stackrel{0}{0}$ & 寊 & 闰 & 空 & 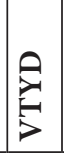 & $\exists$ & 站 & 空 & 贸 & 蛋 & $\sum_{\Sigma}^{Z}$ & $\sum_{\mathbf{L}}$ \\
\hline
\end{tabular}




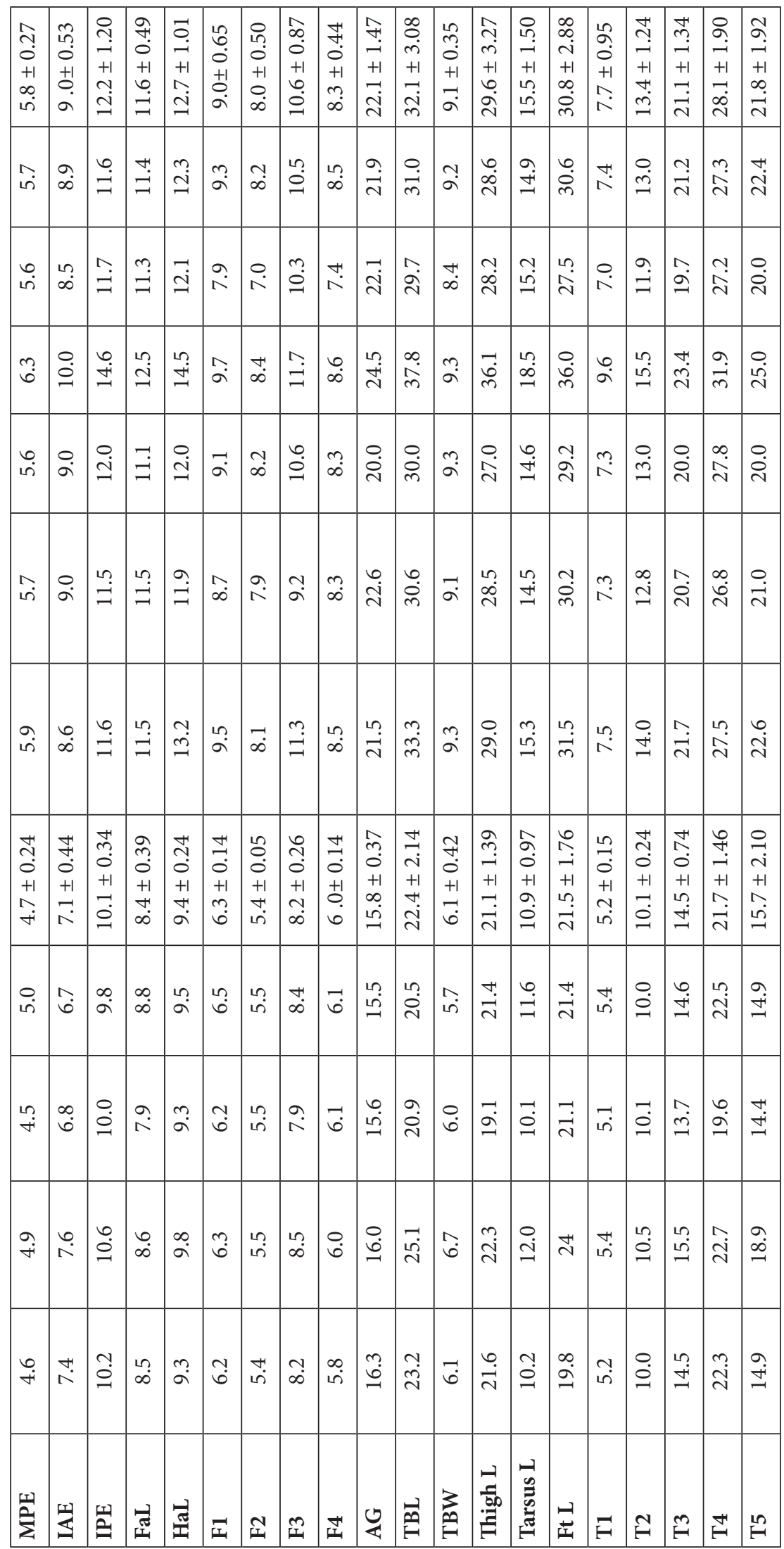




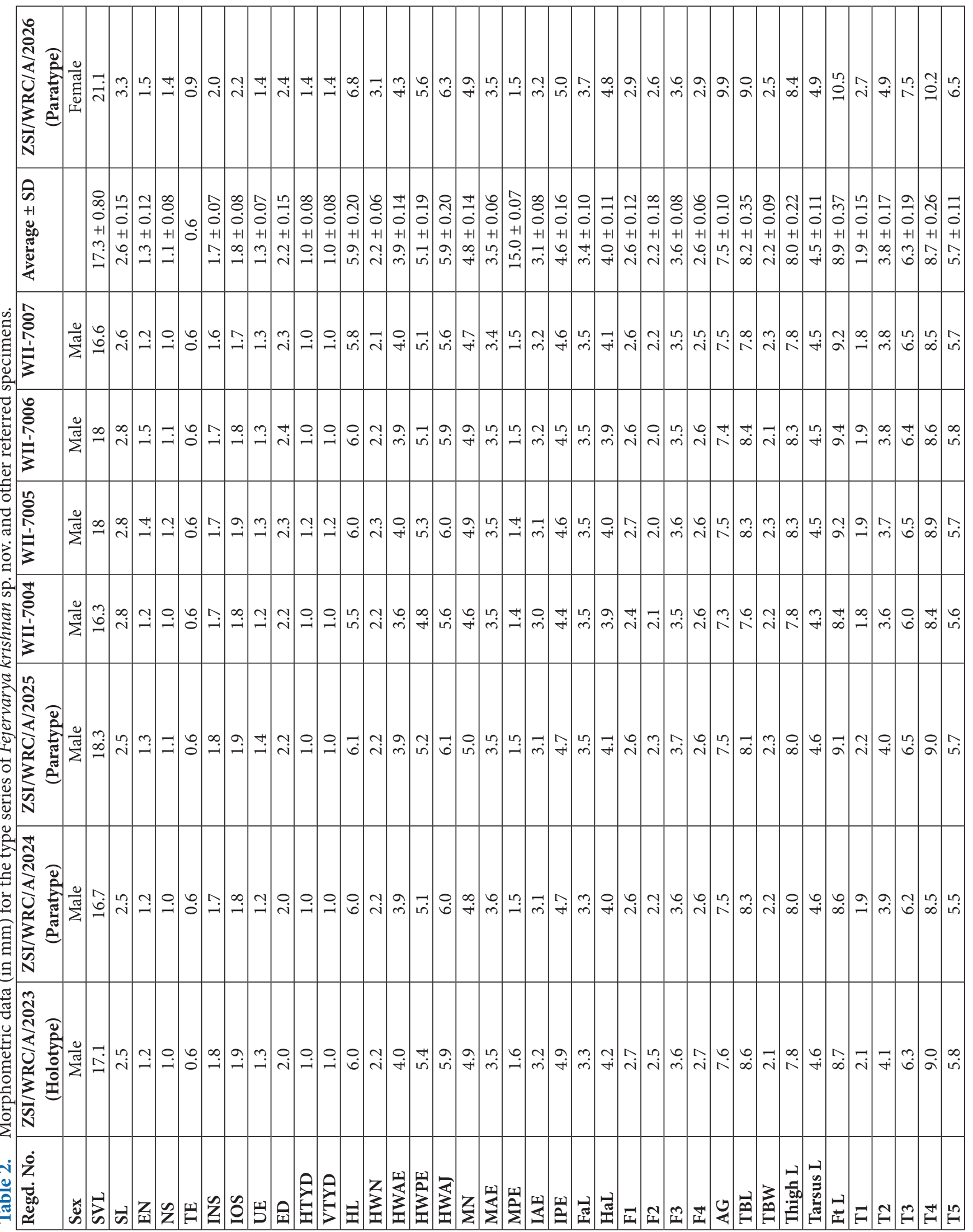




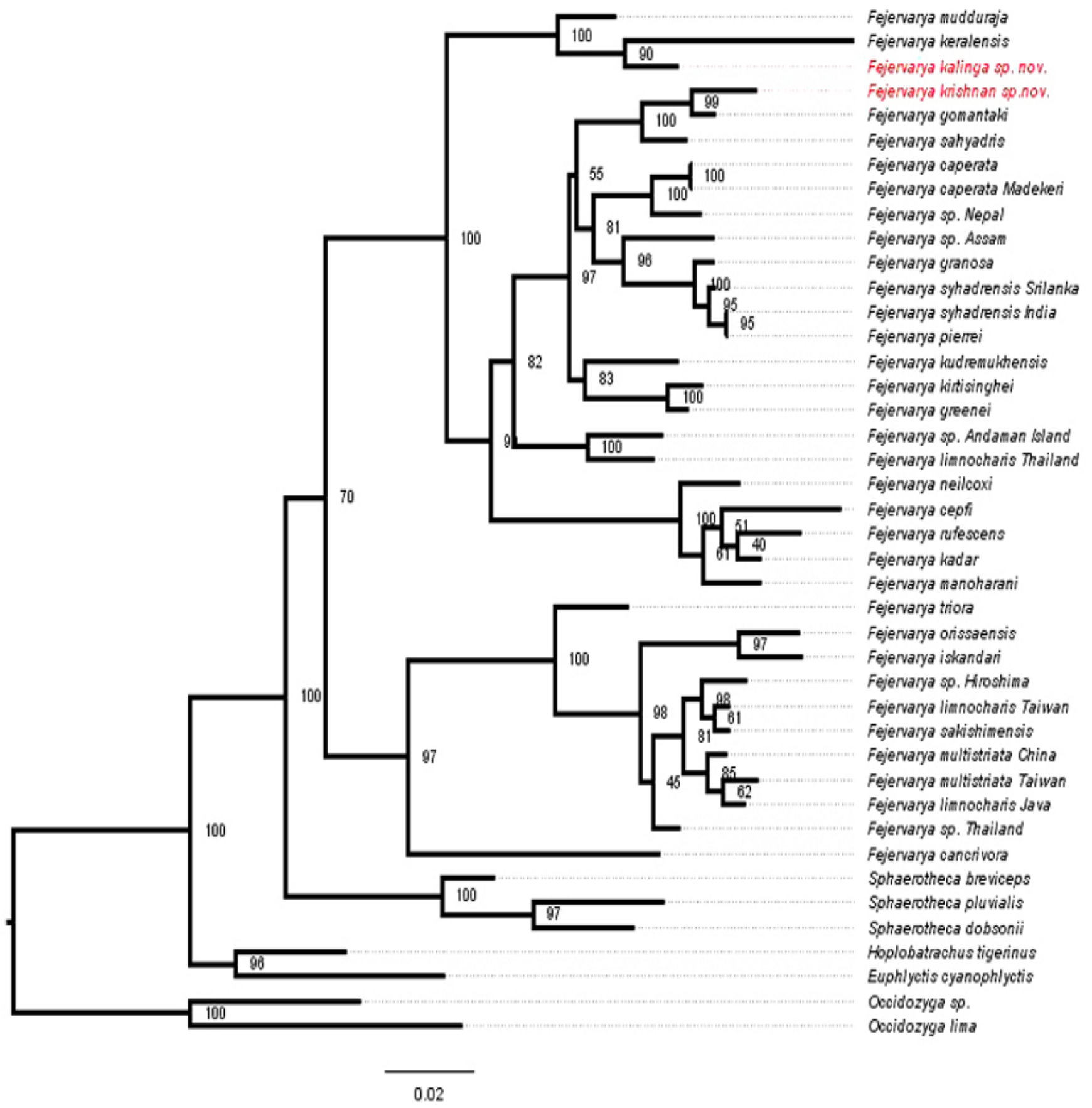

Figure 2. Maximum Likelihood (ML) tree for 42 dicroglossid species based on $5722 \mathrm{bp}$ of mitochondrial and nuclear genes (16s, 12s, BDNF, Rhod, Tyr, RAG-2, NCX1, and CXCR4).

morphological characters including large adult size (mean SVL being $40.4 \mathrm{~mm}$ in males and $54.5 \mathrm{~mm}$ in females); snout pointed in the dorsal and ventral profile; nostrils nearer to snout than to eye; tympanum prominent and more than $50 \%$ of the eye diameter; fore arm shorter than hand; first finger longer than second; hind limbs overlap when folded at right angles to the body, tibio-tarsal articulation reaches the snout tip; thigh length less than tibia length; webbing medium (I 2-1 II 2- 2 III 3-3 IV 3-3 V). 
Description of Holotype (ZSI/WRC/A/2018) (Figures 3 and 4): A large sized Fejervarya species (SVL: 41.9mm) with robust body; head length shorter than head width (HL: 15mm; HW: 15.6mm); snout pointed from above (SL: $7.5 \mathrm{~mm}$ ); canthus rostralis rather angled, loreal region concave with granules; nostrils round and nearer to snout than to eye; upper eyelid width less than eye diameter (UE: $4 \mathrm{~mm}$; ED: $6.5 \mathrm{~mm}$ ); inter narial distance (IN: $3.5 \mathrm{~mm}$ ) slightly greater than inter orbital distance (IOS: $3.5 \mathrm{~mm}$ ); distance between back of eyes 1.4 times more than front of eyes (IAE: $7.4 \mathrm{~mm}$; IPE: $10.2 \mathrm{~mm}$ ); supra-tympanic fold distinct; tympanum prominent and elliptical (HTYD: $4 \mathrm{~mm}$; VTYD:3.8mm) and diameter about $61 \%$ of eye diameter; choanae are widely separated; vomerine teeth long, ellipsoidal and arranged in a single row; anterior part of vomerine teeth series moderately separated from choanae; tip of tongue bifurcated.

Forearm robust (FaL: $8.5 \mathrm{~mm}$ ) and shorter than hand (HAL: $9.3 \mathrm{~mm}$ ); fingers long and moderately thick with rounded tips; no dermal fringes; webbing absent; subarticular tubercles distinct; palmar tubercles present and distinct; then a tubercle oval and prominent; finger lengths $\mathrm{II}<\mathrm{IV}<\mathrm{I}<\mathrm{III}$.

Hind limbs long and overlap when folded at right angles to the body; tibio-tarsal articulation almost reaches the snout tip; thigh length less than tibia length (TBL: $23.2 \mathrm{~mm}$; TiL: $21.6 \mathrm{~mm}$ ); foot length is 1.9 times tarsus length (FtL: $19.8 \mathrm{~mm}, \mathrm{TaL}=10.2 \mathrm{~mm}$ ), relative toe length $\mathrm{I}<\mathrm{II}<\mathrm{III}<\mathrm{V}<\mathrm{IV}$; toe tip rounded; webbing medium (I 2- 1 II 2-2 III 3-3 IV 3-3 V); inner metatarsal tubercle long and oval and outer metatarsal tubercle round and tiny; tarsal fold present; no dermal ridge along outer edge of fifth toe.

Snout and upper eyelid tuberculated with few tiny dermal granules; few tubercles in inter orbital space; lateral side of body with short and slightly thick ridges; numerous longitudinal dermal ridges on the dorsum that are relatively short and arranged randomly; upper part of flank, from arm pit to groin and lower part of flank granular; ventrally smooth on throat, belly and thighs; antero-dorsal region of thighs and dorsal surface of tibia with small granules; tarsus smooth dorsally; few granules around the vent. Supra-tympanic fold prominent, ending at postero-ventral portion of tympanum, reaching up to the base of forelimb.
In preservation, dorsum is dark brown; W-shaped marking present behind the head on the dorsum; groin region speckled; both fore limb and hind limb are prominently barred with dark bands (forearm, dorsal side of thigh, tibia, tarsus and foot); ventrally black marking on throat; belly and rest of the ventral region dirty white.

Secondary Sexual Characters: Males have external vocal sac at the region of throat which is light black in colour and faint nuptial pad present on the first finger.

Additional Information from Paratypes and Referred Specimens: Variation in morphometric characters is shown in Table 1 for comparison. Paratypes resemble the holotype in all aspects of morphology. Mid dorsal line was not observed in any of the specimens used in the current study.

Etymology: The specific epithet is referred to the geographic region of historical Kalinga Kingdom, comprising present day south Odisha and northern Andhra Pradesh between the river Mahanadi and river Godavari in India. The specific name is a noun standing in apposition to the generic name. Suggested common name: 'Kalinga Cricket frog'.

Distribution and Natural History: This species is known with certainty from several locaities in Odisha such as Mahendragiri hills, Gajapati district; Barbara RF, Khordha district; Rajanga, Hindol, Dhenkanal district; Potangi hills, Koraput district and Sorada, Ganjam district. In Andhra Pradesh this species is distributed in Sileru, Visakhapatnam district and Papikonda at Maredumilli, East Godavari district, Andhra Pradesh. Fejervarya kalinga sp. nov. is widely distributed at an elevation range of 600 to $1200 \mathrm{~m}$ ASL in the northern Eastern Ghats that stretches from Mahanadi river in the east to Godavari river in the west, which falls in Eastern Highlands biotic provinces (Rodgers et al., 2000). It inhabits moist deciduous to semi-evergreen forest habitats. The species was observed to breed during winter (November to February) season. Breeding takes place at the edges of streams, in open paddy fields and ditches in swampy grass lands of forested areas.

Comparisons: Fejervarya kalinga sp. nov. is found sympatric with F. orissaensis mostly in the lower altitudes in northern Eastern Ghats. Although, phylogenetically Fejervarya kalinga sp. nov is a member of Western Ghat clade, it can 
be distinguished from F. orissaensis (Figure 5) in having relatively smaller adult male size of SVL 37.0 to $43.4 \mathrm{~mm}$ $(\mathrm{n}=4)$ (vs. relatively larger adult male size of SVL 36.2 to $47.2 \mathrm{~mm}(\mathrm{n}=22)$ in F. orissaensis); larger adult female size of SVL 49.1 to $65.0 \mathrm{~mm} \mathrm{(n=4)} \mathrm{(vs.} \mathrm{relatively} \mathrm{smaller} \mathrm{adult}$ female size of SVL 34.2 to $53.8 \mathrm{~mm}(\mathrm{n}=22)$ in F. orissaensis); head width sub equal to head length (vs. head longer than wide in F. orissaensis); canthus rostralis angular (vs. canthus rostralis obtuse in F. orissaensis); webbing medium (I 2-1 II 2-2 III 3-3 IV 3-3 V) (vs. webbing extensive (I 1-2

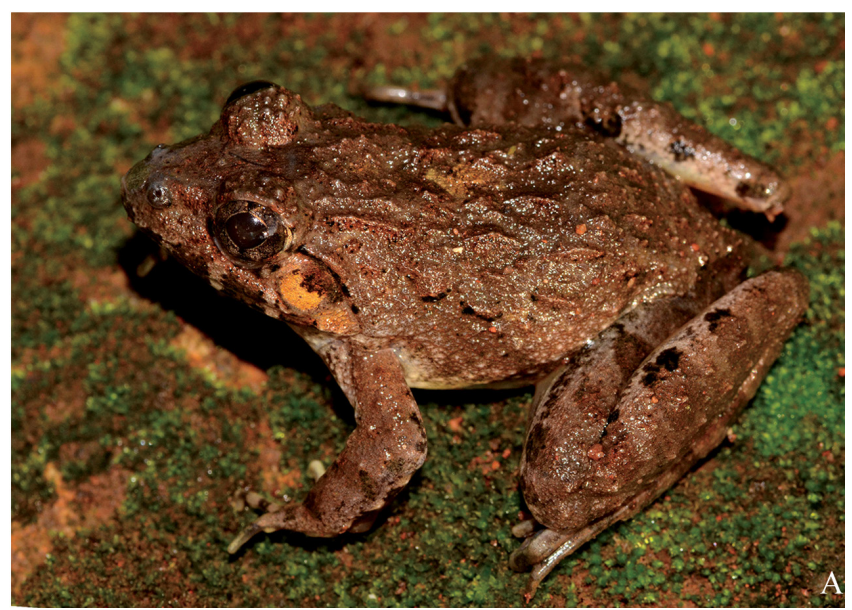

II 1-1 III 1-2 IV 2-1 V) in F. orissaensis); medium to high elevation preference with predominant forested habitat (vs. low elevation preference with predominant human habitation tolerance in F. orissaensis).

Fejervarya kalinga sp. nov. is geographically disjunct (N 18.18; E 77.95) from its phylogenetic sister species $F$. keralensis, distributed in the Western Ghats (N 10.26; E 76.80 ), and both the localities are separated by $850 \mathrm{~km}$ in aerial distance.

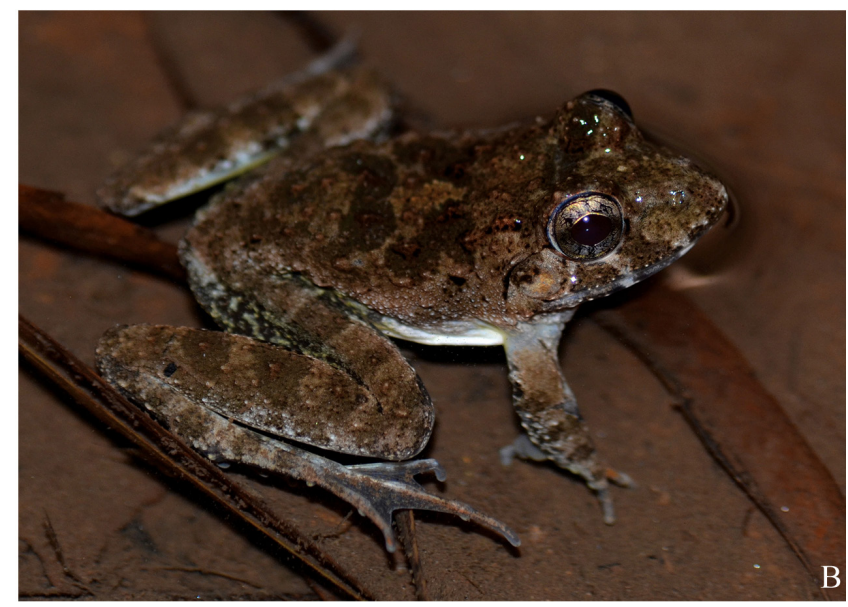

Figure 3. Fejervarya kalinga sp. nov. in life. A. Holotype (ZSI/WRC/A/2018) from Mahendragiri, in life, B. Paratype (ZSI/ WRC/A/2021) from Barbara, in life.
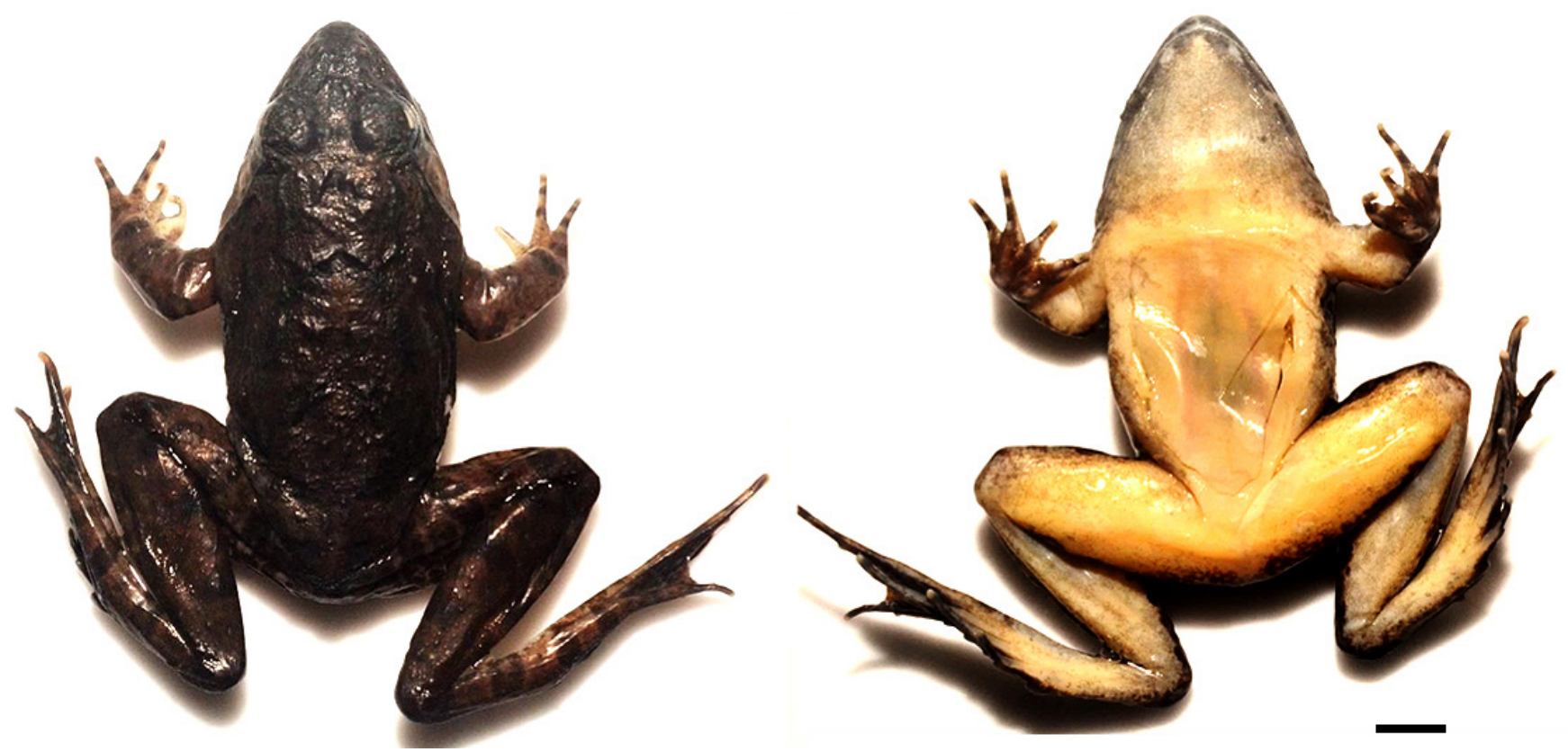

Figure 4. Fejervarya kalinga sp. nov., holotype, ZSI/WRC/A/2018, adult male, $41.9 \mathrm{~mm}$ SVL. Dorsal and ventral view (horizontal lines equal $5.0 \mathrm{~mm}$ ). 


\section{Fejervarya krishnan sp. nov.}

(Table 2, 4; Refer Figures 1,2,6,7 and 8)

Holotype: Adult male: Jog fall, Shimoga district, Karnataka, (N14.219698 ${ }^{\circ}$; E 74.809669 ${ }^{\circ}$ ), Alt. 508m ASL, 10-VII-2015, coll. Prudhvi Raj (ZSI/WRC/A/2023).

Paratypes: Two males and one female: Jog fall, Shimoga district, Karnataka, (N14.219698 ${ }^{\circ}$; E $\left.74.809669^{\circ}\right)$, Alt. 508m ASL, 10-VII-2015, coll. Prudhvi Raj (ZSI/ WRC/A/2024, 2025 \& 2026).

Lineage diagnosis (Figure 2): Fejervarya krishnan sp. nov. can be diagnosed phylogenetically as a member of the fejervaryan clade, showing a sister relationship to $F$. gomantaki exhibiting high level of genetic divergence of $4 \%$ for $16 \mathrm{~S}$ rRNA. It is also morphologically distinct from its sister species (F. gomantaki) (Figure 6).

Morphological diagnosis: This species can be distinguished from its congeners by combination of morphological characters, small size and slender body; head length equal to head width; snout pointed in dorsal aspect; nostrils nearer to snout tip; distinct supra-tympanic; moderately visible tympanum; indistinct vomerine teeth; tongue bifid without a papilla; fore arm shorter than hand; when folded, hind limbs touch at right angles to the body; tibiotarsal articulation reaches back of eyes; thigh length less than tibia length and rudimentary webbing (I 1-1 II 2-2 III 2-3 IV 3-2 V).

In the field, Fejervarya krishnan sp. nov. does not have any morphologically confusing congeneric sympatric species, and can be identified based on the combination of morphological characters including small body size (mean SVL of males being $17.3 \mathrm{~mm}$ ); shorter second finger; less prominent palmar tubercle; absence of vomerine ridge; dorsum light brown with a black streak from the tip of the snout to the supra tympanic fold. For comparisons of the new species Fejervarya krishnan sp. nov. from its morphologically confusing species and probable sympatric congeners, see comparisons below.

This species is known from the medium elevated (500 m) forested landscape of Jog, Shimoga in the central Western Ghats. It is geographically disjunct ( $\mathrm{N}$ 14.22) from its phylogenetic sister species, F. gomantaki (N 15.74) with an isolation of $180 \mathrm{~km}$ aerially. Additional sampling is required to establish the range limits of both the sister lineages and to understand the geographical barrier for isolation of the sister species.

Description of Holotype (ZSI/WRC/A/2023) (Figures 6 and 7): A small sized Fejervarya species (SVL: $17.1 \mathrm{~mm}$ ) with slender body; head length almost equal to head width (HL/HW:1.01); snout pointed in dorsal aspect (SL: $2.5 \mathrm{~mm}$ ); canthus rostralis rather angled with loreal region concave; nostrils oval, nearer to snout tip than to eye; upper eyelid width less than eye diameter (UE/ED: 0.65); inter narial distance (IN: $1.8 \mathrm{~mm}$ ) slightly greater than inter orbital distance (IOS: $1.9 \mathrm{~mm}$ ); distance between back of eyes 1.5 times more than front of eyes (IAE: $3.2 \mathrm{~mm}$; IPE: $4.9 \mathrm{~mm}$ ); supra-tympanic fold distinct; tympanum moderately visible; round (HTYD: 1mm; VTYD:1mm) and diameter about $50 \%$ of eye diameter; choanae widely separated and vomerine teeth are indistinct; tongue bifid without a papilla.

Fore arm feeble (FaL: $3.3 \mathrm{~mm}$ ) and shorter than hand (HAL: $4.2 \mathrm{~mm}$ ); fingers short and thin with blunt tips; no dermal fringes; webbing absent; subarticular tubercles distinct; palmar tubercle present and moderate; finger lengths II $<$ I $=$ IV $<$ III.

Hind limbs short; tibio-tarsal articulation reaches back of eyes; thigh length less than tibia length (TBL: $8.6 \mathrm{~mm}$; TiL: $7.8 \mathrm{~mm}$ ); foot length 1.9 times of tarsus length (FtL: $8.7 \mathrm{~mm}$, TaL: $4.6 \mathrm{~mm}$ ), relative toe length $\mathrm{I}<\mathrm{II}<\mathrm{V}<\mathrm{III}<\mathrm{IV}$ $(\mathrm{FTL}=8.7 \mathrm{~mm})$, toe tip rounded; webbing rudimentary (I 1-1 II 2-2 III 2-3 IV 3-2 V); inner metatarsal tubercle long and oval and outer metatarsal tubercle round and tiny, no dermal ridge along outer edge of fifth toe.

Snout smooth with no dermal granules; no tubercles in inter orbital space or on upper eyelid; skin on the dorsum and flanks smooth; no longitudinal glandular folds on the dorsum; ventrally smooth on throat and belly but granular at the region of thighs; anterio-dorsal region of thigh smooth; dorsal surface of tibia and tarsus with small granules; slightly granulated around the vent.

In preservation, dorsum is light brown; black streak runs laterally from tip of snout to canthus rostralis and faintly ending along the groin; lips and rictal gland yellowish; fore limb faintly barred; cross bars on anterior part 
Table 3. Factor loadings of Principal Component Analysis for 8 morphometric characters of males belonging to Fejervarya kalinga sp. nov. and F. orissaensis

\begin{tabular}{|l|l|l|l|l|l|}
\hline Males & PC 1 & PC 2 & PC 3 & PC 4 & PC 5 \\
\hline SVL & 0.82768 & 0.05288 & -0.35442 & 0.24448 & -0.19587 \\
\hline SL & 0.35995 & -0.62332 & 0.60239 & 0.10047 & -0.04955 \\
\hline INS & 0.02348 & -0.00309 & 0.01093 & 0.10144 & -0.03084 \\
\hline HTYD & 0.02279 & 0.18168 & -0.03698 & -0.07682 & 0.06949 \\
\hline HL & 0.26779 & 0.00433 & 0.17975 & -0.47840 & 0.72830 \\
\hline HW & 0.19490 & 0.17931 & -0.27654 & 0.19595 & 0.48413 \\
\hline T4 & 0.02435 & 0.57214 & 0.58090 & 0.53899 & 0.12307 \\
\hline TBL & 0.27205 & 0.46493 & 0.25257 & -0.59681 & -0.41647 \\
\hline
\end{tabular}

Table 4. Factor loadings of Principal Component Analysis for 18 morphometric characters of males belonging to Fejervarya krishnan sp. nov. F. chilapata, F. sahyadris and F. gomantaki.

\begin{tabular}{|c|c|c|c|c|c|}
\hline Males & PC 1 & PC 2 & PC 3 & PC 4 & PC 5 \\
\hline HW & 0.01442 & -0.23772 & 0.62947 & 0.27566 & 0.06296 \\
\hline HL & -0.18452 & 0.17651 & 0.59645 & 0.06759 & -0.17511 \\
\hline MN & -0.28723 & 0.51689 & 0.02926 & -0.18155 & -0.07604 \\
\hline MFE & -0.29199 & 0.45040 & 0.07789 & -0.17310 & -0.00297 \\
\hline MBE & -0.29299 & 0.26033 & -0.02875 & 0.07125 & 0.07813 \\
\hline IFE & -0.03551 & -0.06328 & 0.23014 & -0.03601 & 0.31465 \\
\hline IBE & -0.03121 & -0.05754 & 0.25439 & -0.18926 & 0.41091 \\
\hline FLL & -0.04902 & 0.05365 & -0.09109 & -0.05528 & 0.50509 \\
\hline HAL & 0.04901 & 0.07634 & -0.22205 & 0.21918 & 0.37103 \\
\hline TFL & 0.29050 & -0.00806 & 0.10501 & 0.00970 & 0.13130 \\
\hline TiL & 0.07110 & 0.15820 & 0.04536 & -0.16449 & 0.50000 \\
\hline FOL & 0.07893 & 0.35363 & -0.05437 & 0.81787 & 0.07858 \\
\hline FTL & 0.77988 & 0.45164 & 0.15152 & -0.19088 & -0.10686 \\
\hline IN & -0.00125 & -0.01428 & 0.07324 & -0.00541 & 0.05199 \\
\hline $\mathrm{NE}$ & -0.01971 & 0.04709 & -0.01264 & 0.03218 & -0.01325 \\
\hline EL & -0.02723 & 0.03022 & 0.06536 & 0.03500 & -0.00594 \\
\hline TYD & 0.00186 & -0.02483 & 0.12723 & -0.11644 & 0.00968 \\
\hline TE & 0.00835 & -0.02086 & 0.00193 & 0.12196 & 0.07075 \\
\hline
\end{tabular}


of thigh, tibia, tarsus and foot though not prominent; ventrally throat and thighs cream yellow while the belly is dirty white: external vocal sac at the region of throat which is light black in colour; faint nuptial pad present on the first finger.

Secondary Sexual Characters: Adult males have an external vocal sac at the region of throat which is mostly light black in colour, faint nuptial pad present on the first finger.

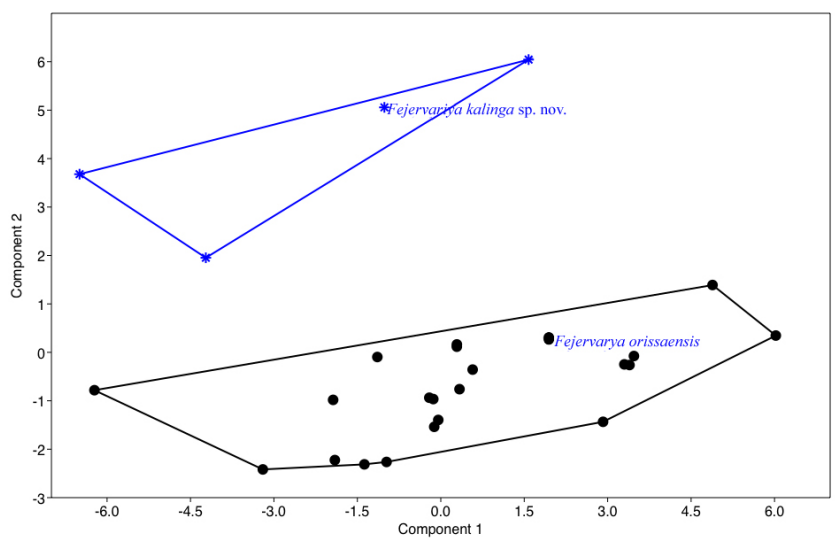

Figure 5. Principal Component Analysis scatter plot (of 18 morphometric characters as listed in Table 3 transformed to their ratio to SVL) for Fejervarya kalinga sp. nov. and F. orissaensis (male individuals).

Additional Information from Paratypes and Referred Specimens: Variations in morphometric characters are shown in Table 2 for comparison. Paratypes resemble the holotype in all aspects of morphology. All male specimens had vocal sacs while the female doesn't. Variation in dorsal coloration is also observed in WII-7004 and WII7006 where the bands on the hind limbs were prominent. Mid dorsal line was found in the female studied and in males of the accession number WII-7005 to WII-7007.

Etymology: The specific epithet 'Krishnan' is named after late Dr K. S. Krishnan (Kozhalmannom Subrammaniasastri Krishnan) for his contribution in the field of biological sciences and being one of the key persons in embarking School in Herpetology sponsored by Department of Science and Technology. The specific name is a noun standing in apposition to the generic name. Suggested common name: 'Jog Krishnan cricket frog'
Distribution and natural history: At present Fejervarya krishnan sp. nov. is known only from the type locality, i.e., in Jog fall, Shimoga district, Karnataka falling in 5B biogeographic zone of Western ghats (Rodgers et al., 2000). However, it is assumed that this species could be more widely distributed and additional sampling is required to understand the distribution range limits of the species.

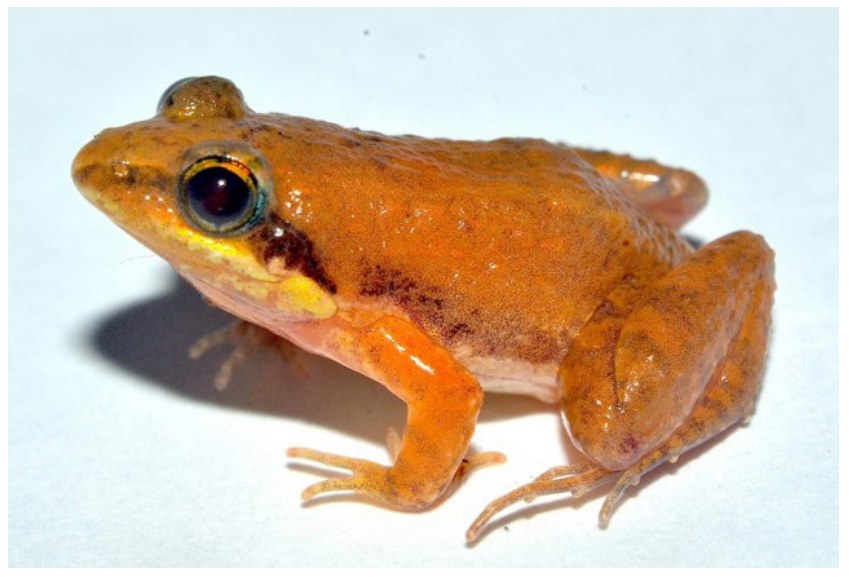

Figure 6. Fejervarya krishnan sp. nov. in life.

Comparisons: The other species of Fejervarya reported in the surroundings of the type locality of Fejervarya krishnan sp. nov. are F. modesta (species needs validation), F. mysorensis (no collections after original descriptions), F. caperata and F. granosa. But, Fejervarya krishnan sp. nov. can be easily distinguished from these sympatric congeneric species in having a smaller body size, possession of rictal gland and white upper lip. The other small species of Fejervarya that could be confused due to possession of rictal gland and white upper lip include F. gomantaki, F. sahyadris and F. chilapata. PCA analysis comparing the new species with its phylogenetic sister and the other confusing probable sympatric species suggest a substantial morphological separation between Fejervarya krishnan sp. nov. and others (F. gomantaki, F. sahyadris and F. chilapata) (Figure 6). PC1 accounted for $55 \%$ variance and PC2 accounted for 25\% variance.

Fejervarya krishnan sp. nov. is having second finger shortest (vs. finger I shortest in F. chilapata); dorsum of the body cream brown with number of broken ridges, dark streak from the tip of snout ending at the supratympanic fold and limbs with faint cross bands (vs. dorsal parts of head and body greyish beige with light orange 


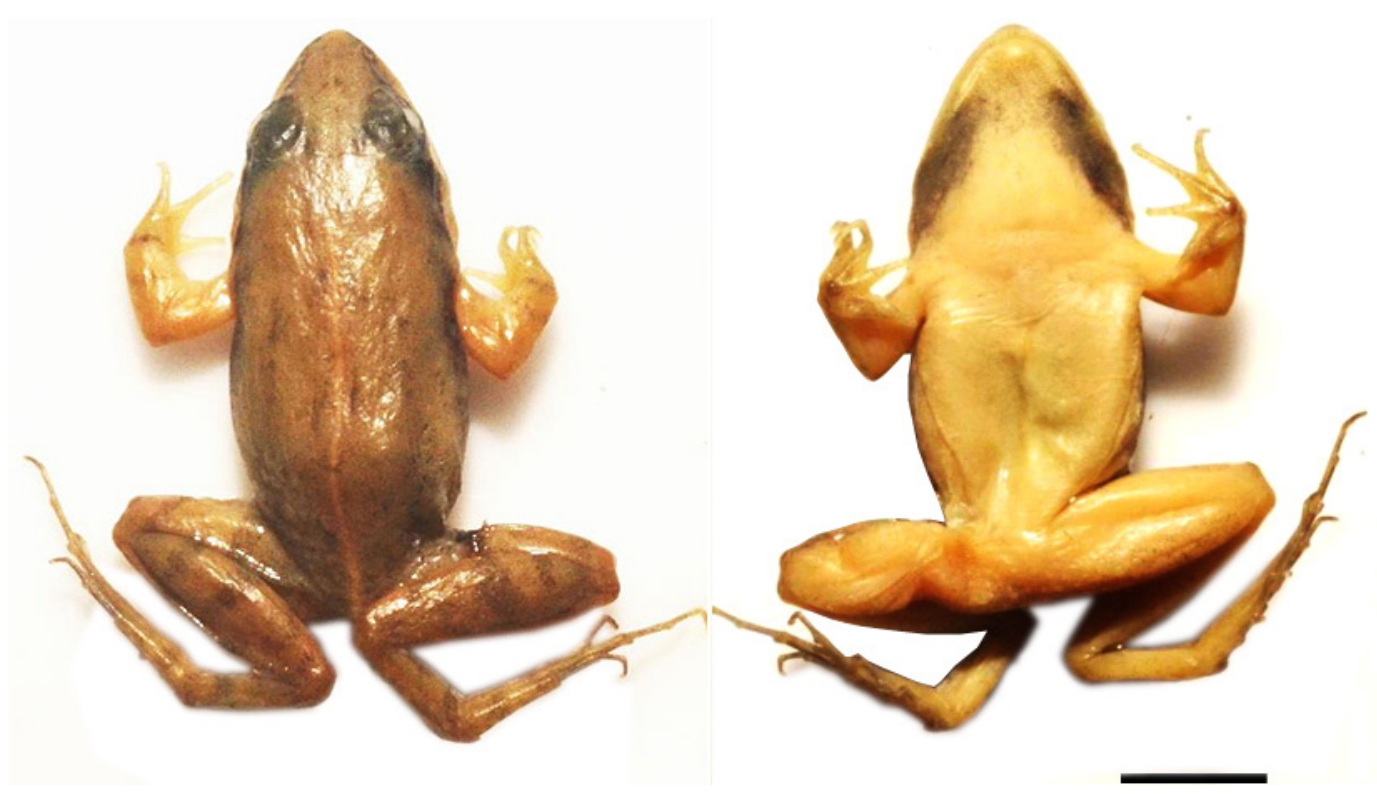

Figure 7. Fejervarya krishnan sp. nov., holotype, ZSI/WRC/A/2023, adult male, $17.1 \mathrm{~mm}$ SVL. Left, dorsal view; right, ventral view (horizontal lines equal $5.0 \mathrm{~mm}$ ).

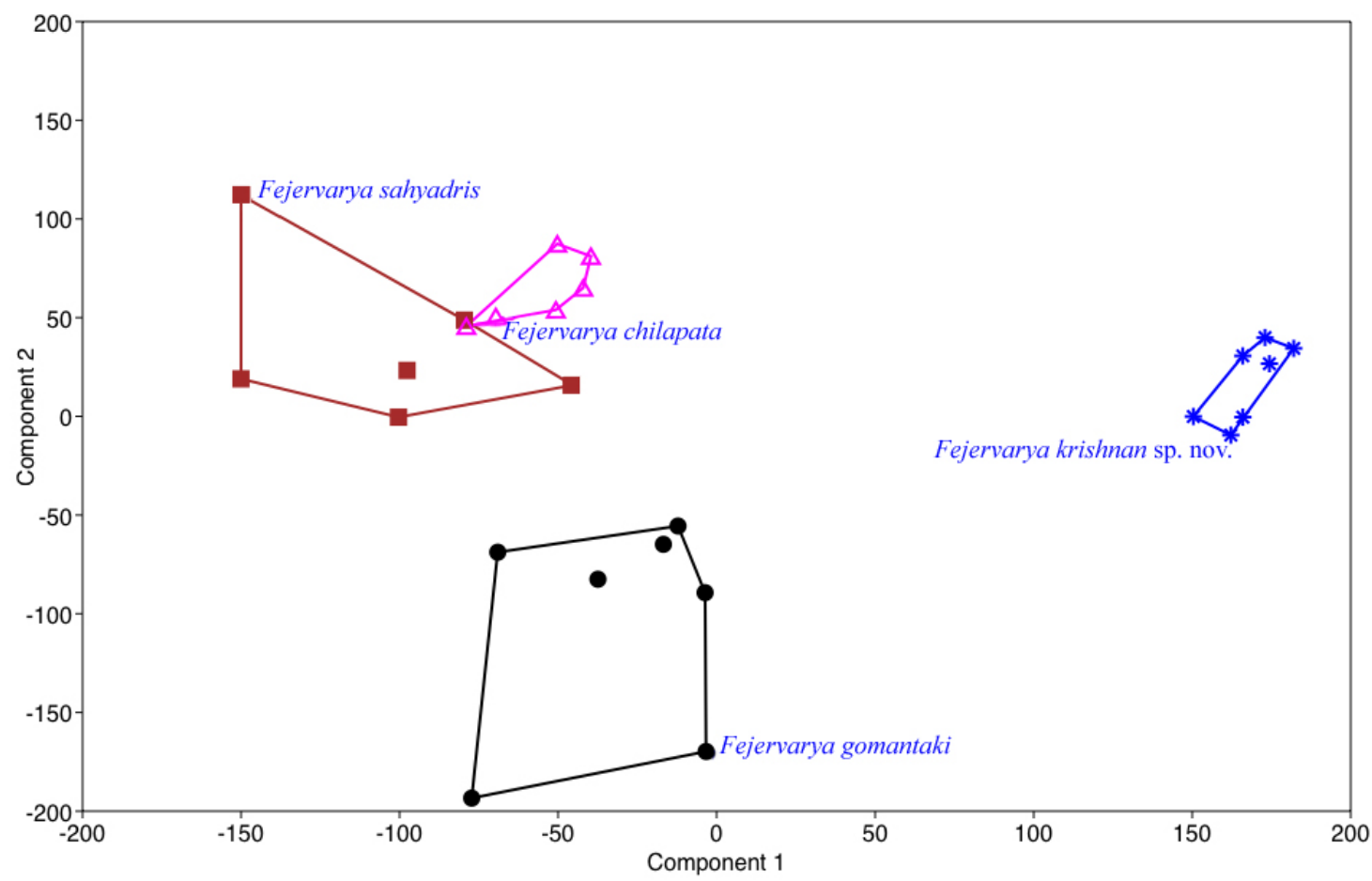

Figure 8. Principal Component Analysis scatter plot (of 18 morphometric characters as listed in Table 3 transformed to their ratio to SVL) for Fejervarya krishnan sp. nov., F. gomantaki, F. sahyadris and F. chilapata (a) for male individuals. 
mid-dorsal line, dark streak from the tip of snout passing through canthus rostralis and ending in the second half of groin and hind limbs with dark cross bar in F. chilapata). Adult males of F. krishnan have a lower SVL of $17.3 \mathrm{~mm}$ $\pm 0.80, \mathrm{n}=7$ (vs. greater SVL of $20.0 \mathrm{~mm} \pm 6.95, \mathrm{n}=8$ in $F$. chilapata); smaller MN/SVL ratio of 0.280 (0.272 to 0.287 , $\mathrm{n}=7$ ) (vs. greater MN/SVL ratio of 0.364 (0.330-0.384, $\mathrm{n}=8)$ in F. chilapata); lower MPE/SVL ratio of $0.086(0.074$ to $0.098, \mathrm{n}=7$ ) (vs. greater MPE/SVL ratio of $0.157(0.128$ to $0.174, \mathrm{n}=7$ ) F. chilapata).

Fejervarya krishnan sp. nov. is having second finger shortest (vs. finger I shortest in F. gomantaki); palmer tubercle less distinct (vs. palmer tubercle not distinct in F. gomantaki); dorsum of the body cream brown with number of broken ridges, dark streak from the tip of snout ending at the supratympanic fold and limbs with faint cross bands (vs. brown dorsum, dark streak from the tip of snout passing through canthus rostralis and ending in the second half of groin and hind limbs with dark cross bar in F. gomantaki). Adult males of Fejervarya krishnan have a lower SVL of $17.3 \mathrm{~mm} \pm 0.80, \mathrm{n}=7$ (vs. $19.3 \mathrm{~mm} \pm 0.68, \mathrm{n}=7$ in $F$. gomantaki); lower MPE/SVL ratio of 0.086 ( 0.074 to $0.098, n=7$ ) (vs. greater MPE/SVL ratio of $0.116(0.100$ to $0.129, \mathrm{n}=7)$ in F. gomantaki).

Fejervarya krishnan sp. nov. is having second finger shortest (vs. finger IV shortest in F. sahyadris); palmer tubercle less distinct (vs. palmer tubercle distinct in F. sahyadris); vomerine ridge absent (vs. vomerine ridge present in Fejervarya sahyadris); dorsum of the body cream brown with number of broken ridges, dark streak from the tip of snout ending at the supratympanic fold and limbs with faint cross bands (vs. dorsum brick red to dark brown, dark streak from the snout ends at the supratympanic fold, limbs with faint cross bars in F. sahyadris). Adult males of Fejervarya krishnan have a lower SVL of $17.3 \mathrm{~mm}$ $\pm 0.80, \mathrm{n}=7$ (vs. $18.4 \mathrm{~mm} \pm 6.01, \mathrm{n}=10$ in F. sahyadris); smaller MN/SVL ratio of 0.280 (0.272 to $0.287, \mathrm{n}=7$ ) (vs. greater MN/SVL ratio of 0.360 (0.353 to $0.371, \mathrm{n}=10$ ) in F. sahyadris); lower MPE/SVL ratio of $0.086(0.074$ to $0.098, \mathrm{n}=7$ ) (vs. greater MPE/SVL ratio of $0.168(0.153$ to $0.178, \mathrm{n}=10)$ in $F$. sahyadris); lower TBL/SVL ratio of $0.463(0.437$ to $0.479, \mathrm{n}=7)$ (vs. greater TBL/SVL ratio of $0.429(0.423$ to $0.434, \mathrm{n}=10)$ in F. sahyadris $)$.

\section{Discussion}

Although 29 species of Fejervarya are reported from India (Dinesh et al., 2017), considering their morphological crypticity, there are many possibilities of occurrence of many described species distributed in wide range and even some species new to science. During the description of a new species from the Western Ghats Dinesh et al., (2015) have cleared the generic level ambiguity within the family (Dicroglossidae) for the genus Fejervaryal Minervaryal Zakerana demonstrating the overlapping distribution range among the members of these 'clades' and the absence of distinct morphological characters to recognize the above said genera. Recently, Garg and Biju (2017), while describing four new species from the Western Ghats, provided four distinct morphological groups for the extant 20 species of Fejervarya for this biogeographic region. The present study shows that Fejervarya krishnan sp. nov. is sister to the small-sized F. gomantaki (having its range of distribution in the Western Ghats), which in turn nested in the clade having species representations predominantly from south Asia (Dinesh et al., 2015). Furthermore, the large species Fejervarya kalinga sp. nov., from the Eastern Ghats, is phylogenetic sister to the other large species F. keralensis (having its range of distribution in the Western Ghats). On the other hand F. orissaensis, the probable sympatric species of Fejervarya kalinga sp. nov., is showing phylogenetic sister relationship with $F$. iskandari within the large-bodied Fejervarya clade having species representations predominantly from east/south east Asia (Dinesh et al., 2015). This pattern of small species having phylogenetic sister in the shorter geographical range and the larger species having phylogenetic sister in the distant geographical range could be indication of either poor species representations for the phylogenetic studies or the big sized species could have a wide range of distribution. Under these circumstances, morphological groupings (Garg and Biju, 2017) for the groups (genus) non endemic to biogeographic zones could be dubious. A systematic field sampling and phylogenetic studies across the entire distribution range of Fejervarya could address such taxonomic problems and the phylogenetic patterns discussed above.

Considering the vastness of the geographical area of the Eastern Ghats, the species representation is very poor 
(2 species) when compared to the Western Ghats (20 species). This indicates the paucity of systematic work in the Eastern Ghats biogeographic zone. Earlier works on fauna of Eastern Ghats (Guptha et al., 2012; Deuti et al., 2014) reported assurance F. limnocharis, F. keralensis and F. orissaensis from Eastern Ghats. However, report of the former two from this region might be a case of mistaken taxonomic identity in view of the fact that during the current study neither of the two species was recorded even after extensive field surveys. In recent years, herpetological studies have discovered few endemic species from the region (Giri et al., 2017) which warrants the need for further systematic surveys on this region.

Fejervarya kalinga sp. nov. is known from a wide range of distribution from Godavari river basin to Mahanadi river basin and the species Fejervarya krishnan sp. nov. is known only from the surroundings of the type locality. Hence, we propose 'Data Deficient' status for both the species in IUCN Red List, until further systematic field samplings.

\section{Acknowledgements}

We would like to thank the Director and Dean, FWS Wildlife Institute of India (WII), Dehra Dun for being a source of encouragement and guidance during the study. We are thankful for Department of Biotechnology for awarding Research Associate-ship to the first author to undertake the current study. KPD and PPM are indebted to Dr Kailash Chandra, Director, Zoological Survey of India (ZSI), Kolkata; Dr P.S. Bhatnagar, Officer-in-charge, ZSI, WRC, Pune; Dr S. Sambath, Officer-in-charge, ZSI, CZRC, Jabalpur and Shri Rati Ram Verma, Publication Production Officer, ZSI, Kolkata for encouragement. At the Indian Institute of Sciences (IISc), Centre for Ecological Sciences (CES), we are indebted to the Chairperson for granting the permission to carry out all the molecular work at TE-11 lab; Dr Praveen Karanth for the financial and logistics support and his lab members Deepak Veerapan, Aniruddha Dutta-Roy, Aprna Lajmi, Kunal Arekar, Maitriya Sil, Chinta Sidharthan, Ananya Jana and Anjali Verma for the support in the wet lab. We would like to express our gratitude to IISc, CES, Evolutionary Ecology Lab of Dr Kartik Shanker for the Open Taxonomy Initiative and his lab members Dr. S.P. Vijay Kumar, Varun Torsekar, Aditi Jayarajan and Priyanka Swamy for their support during the course of the work. We would like to thank Deepan Chackaravarthy for his assistance in preparing the species distribution map. KPD is thankful to DBT and SERB (SR/FR/LS-88/210/09.05.2012) for fellowship and financial assistance to conduct part of this work. PPM is thankful to Soubhagya Sahu, reader in History, Government Science College, Chatrapur for clarification regarding history of Kalinga.

\section{References}

Biju, S.D. and Bossuyt, F. 2003. New frog family from India reveals an ancient biogeographical link with the Seychelles. Nature. 425: 711-714.

Bossuyt, F. and Milinkovitch, M.C. 2000. Convergent adaptive radiations in Madagascan and Asian ranid frogs reveal covariation between larval and adult traits. Proc. Natl. Acad. Sci. U.S.A.. 97(12): 6585-6590.

Chanda, S.K. 2002. Hand Book Indian Amphibians: 1-335, Published by Zool. Surv. India.

Dahankur, N., Sulakhe, S. and Padhye, A. 2017. Identity of Sphaerotheca pulvialis (Jerdon, 1853) and other available names among the burrowing frogs (Anura:Dicroglossidae) of South Asia. J. Threastened Taxa, 9(6): 10269-10285.

Daniels, R.J.R. 1992. Geographical distribution patterns of amphibians in the Western Ghats, India.J. Biogeogr. 19(5): 521-529.

Daniels, R.J.R. 2005. Amphibians of Peninsular India: 1-268, Published by Indian Acad. Sci. and Uni. Press, Hyderabad.

Das, I. and Dutta, S.K. 1998. Checklist of the amphibians of India, with English common names. Hamadryad. 23: 63-68.

Deuti, K., Sethy, P.G.S. and Ray, S. 2014. Amphibians of the Eastern Ghats. Rec. Zool. Surv. India. 114 (Part-1): $119-144$.

Dinesh, K.P., Vijayakumar, S.P., Murthy, B.H.C, Torsekar, V.R., Kulkarni, N.U. and Shanker, K. 2015. Systematic status of Fejervarya ((Amphibia, Anura, Dicroglossidae) from South and SE Asia with the description of a new species from the Western Ghats of Peninsular India. Zootaxa. 3999(1): 79-94.

Dinesh, K.P., Radhakrishnan, C., Murthy, B.H.C, Deepak, P. and Kulkarni, N.U. 2017. A Checklist of Amphibians of India with IUCN conservation status (updated till September 2017). Available from: http://zsi.gov.in/WriteReadData/userfiles/file/Checklist/ Amphibia_Checklist_2017.pdf

Djong H.T., Islam M.M., Nishioka M., Matsui M., Ota H., Kuramoto M., Khan M. M. R., Alam M. S., De Silva A., Khonsue W. and Sumida M. 2007. Genetic relationships and reproductive isolation mechanism among the Fejervarya limnocharis complex from Indonesia (Java) and other Asian countries. Zool. Sci. 24: 360-375. 
Dubois, A. 1975. Un nouveau complexe d' espèces jumelles distinguées par le chant: les grenouilles du Nèpalvoisines de Rana limnocharis Boie (Amphibiens, Anoures). C. R. Acad. Sci., 218: 1717-1720.

Dubois, A. 1987 “1986”. Miscellanea taxinomica batrachologica (I). Alytes. 5: 7-95.

Dubois, A. 1999. South Asian Amphibia: a new frontier for taxonomists. J. South Asian Nat. Hist. 4(1): 1-11.

Dutta, S.K. and Manamendra-arachchi, K. 1996. The Amphibian Fauna of Sri Lanka: 1-230, Published by Wildlife Heritage Trust of Sri Lanka. Colombo.

Dutta, S.K. and Singh. N. 1996. Status of Limnonectes limnocharis (Anura: Ranidae) species complex in Asia. Zoos Print J. 11(8): 15-21.

Dutta, S.K., Vasudevan, K., Chaitra, M.S., Shankar, K. and Aggarwal, R.K. 2004. Jurassic frogs and the evolution of amphibian endemism in the Western Ghats. Curr. Sci. 86: 211-216.

Fei, L., Ye, C.Y., Jiang, J.P. and Xie, F. 2002. On taxonomic status of Rana limnocharis group with revision of nomenclature of the rice frog from China. Herpetol. Sin. 9: 88-96.

Frost, D.R. 2018. Amphibian species of the world: an online reference. Version 6.0. American Museum of Natural History, New York, USA. Available from: http://research.amnh.org/herpetology/amphibia/index.html

Frost, D.R., Grant, T., Faivovich, J., Bain, R.H., Haas, A., Haddad, C.F.B., de Sá, R.O., Channing, A., Wilkinson, M., Donnellan, S.C., Raxworthy, C.J., Campbell, J.A., Blotto, B.L., Moler, P.E., Drewes, R.C., Nussbaum, R.A., Lynch, J.D., Green, D.M. and Wheeler, W.C. 2006. The amphibian tree of life. Bull. Am. Mus. Nat. Hist. 297: 1-370.

Garg, S. and Biju, S.D. 2017. Description of four new species of Burrowing Frogs in the Fejervarya rufescens complex (Dicroglossidae) with notes on morphological affinities of Fejervarya species in the Western Ghats. Zootaxa. 4277(4): 451-490.

Giri, V.B., Bauer, A.M., Mohapatra, P.P., Srinivasulu, C. and Agarwal, I. 2017. A new species of large-bodied, tuberculate Hemidactylus Oken (Squamata: Gekkonidae) from the Eastern Ghats, India. Zootaxa. 4347(2): 331-345.

Guptha, M.B., Rao, P.V.C., Prasad, N.V.S., Maddala, S.R.S.C.S., Babu, P.M. and Reddy, D.S. 2012. Status of Herpetofauna in Seshachalam Biosphere Reserve, Eastern Ghats, Andhra Pradesh, India. World J. Zool. 7(2): 131-134.

Hammer, O., Harper, D.A.T. and Ryan, P.D. 2001. PAST: Paleontological statistics software package for education and data analysis. Palaeontol. Electron. 4(1): 1-9.

Hasan, M., Islam, M.M., Khan, M.M.R., Alam, M.S., Kurabayashi, A., Igawa, T., Kuramoto, M. and Sumida, M. 2012. Cryptic anuran biodiversity in Bangladesh revealed by mitochondrial 16S rRNA gene sequences. Zool. Sci., 29(3): 162-172.

Howlader, M.S.A. 2011. Cricket frog (Amphibia: Anura: Dicroglossidae): two regions of Asia are corresponding two groups. BNNOPRANI: Bd. Wl. Bull. 5: 1-7.

Islam, M.M., Kurose, N., Khan, M.M.R., Nishizawa, T., Kuramoto, M., Alam, M.S., Hasan, M.K., Kurniawan, N., Nishioka, M. and Sumida, M. 2008. Genetic divergence and reproductive isolation in the genus Fejervarya (Amphibia: Anura) from Bangladesh inferred from morphological observations, crossing experiments, and molecular analyses. Zool. Sci. 25(11): 1084-1105.

Kurabayashi, A., Kuramoto, M., Joshy, S.H. and Sumida, M. 2005. Molecular phylogeny of the ranid frogs from southwest India based on the mitochondrial ribosomal RNA gene sequences. Zool. Sci. 22(5): 525-534.

Kuramoto, M., Joshy, S.H., Kurabayashi, A. and Sumida, M. 2008 “2007”.The genus Fejervarya (Anura: Ranidae) in central Western Ghats, India, with descriptions of four new cryptic species. Curr. Herpetol. 26: 81-105.

Matsui, M., Toda, M. and Ota, H. 2008 “2007”. A new species of frog allied to Fejervarya limnocharis from southern Ryukyuas, Japan (Amphibia: Ranidae). Curr. Herpetol., 26: 65-79.

Myers, C.W. and Duellman, W.E. 1982. A new species of Hyla from Cerro Colorado, and other tree frog records and geographical notes from Western Panama. Am. Mus. Novit., 2752: 1-32.

Meenakshi, K., Suraj, T., Bhagwati, S.S., Sujith, V.G., Santhoshkumar, K. and Sanil, G. 2010. Molecular resolution of four Fejervarya Species from Western Ghats (India) with their intrageneric phylogeny based on COI, Cyt B, 12S and 16S rRNA Genes. Asian J. Exp. Biol. Sci. 1(4): 782-786.

Ohler, A., Deuti, K., Grosjean, S., Paul, S., Ayyaswamy, A.K., Ahmed, M.F. and Dutta, S.K. 2009. Small-sized dicroglossids from India, with the description of a new species from West Bengal, India. Zootaxa. 2209: 43-56.

Ohler, A., Dutta, S.K. and Dubois, A. 2014. Morphological evolution in frogs of the genera Fejervarya, Minervarya, Sphaerotheca and Zakerana (Dicroglossidae). Pranikee-J. Zoo. Soc. Orissa. 16: 1-12.

Palumbi, S.R., Martin, A., Romano, S., Owen, MacMillan W., Stice L. and Grabowski C. 1991. The Simple Fool's Guide to PCR: 1-45. Published by Dept. Zool., Univ. Hawaii, Honolulu.

Rodgers W.A., Panwar, H.S., Mathur, V.B. 2000. Wildlife Protected Area Network in India: A Review (Executive Summary). Wildlife Institute of India, Dehradun, 53pp.

Stamatakis A. 2014. RAxML version 8: a tool for phylogenetic analysis and post-analysis of large phylogenies. Bioinformatics. 30: $1312-1313$.

Sumida, M., Ogata, M., Kaneda, H. and Yonekawa, H. 1998. Evolutionary relationships among Japanese pond frogs inferred from mitochondrial DNA sequences of cytochrome b and 12S ribosomal RNA genes. Genes Genet. Syst. 73: 121-133. 
Sumida, M., Kondo, Y., Kanamori, Y. and Nishioka, M. 2002. Inter and intraspecific evolutionary relationships of the rice frog Rana limnocharis and the allied species R. cancrivora inferred from crossing experiments and mitochondrial DNA sequences of the $12 \mathrm{~S}$ and 16S rRNA genes. Mol. Phylogenet. Evol. 25: 293-305.

Sumida, M., Kotaki, M., Islam, M.M., Djong, T.H., Igawa, T., Kondo, Y., Matsui, M., De Silva, A., Khonsue, W. and Nishioka, M. 2007. Evolutionary relationships and reproductive isolating mechanisms in the rice frog (Fejervarya limnocharis) species complex from Sri Lanka, Thailand, Taiwan and Japan, inferred from mtDNA gene sequences, allozymes, and crossing experiments. Zool. Sci., 24(6): 547-562.

Toda, M., Matsui, M., Nishida, M. and Ota, H. 1998. Genetic divergence among southeast and East Asian populations of Rana limnocharis (Amphibia: Anura), with special reference to sympatric cryptic species in Java. Zool. Sci. 15: 607-613.

Van Bocxlaer, I., Roelants, K., Biju, S.D., Nagaraju, J. and Bossuyt, F. 2006. Late Cretaceous vicariance in Gondwanan amphibians. Plos One. 1(1): e74.

Vences, M., Thomas, M., Bonett, R.M. and Vieites, D.R. 2005. Deciphering amphibian diversity through DNA barcoding: chances and challenges. Philos. Trans. R. Soc. Lond. B Biol. Sci. 360: 1859-1868.

Vijayakumar, S.P., Dinesh, K.P., Prabhu, M.V. and Shanker, K. 2014. Lineage delimitation and description of nine new species of bush frogs (Anura: Raorchestes, Rhacophoridae) from the Western Ghats Escarpment. Zootaxa. 3893: 451-488. 


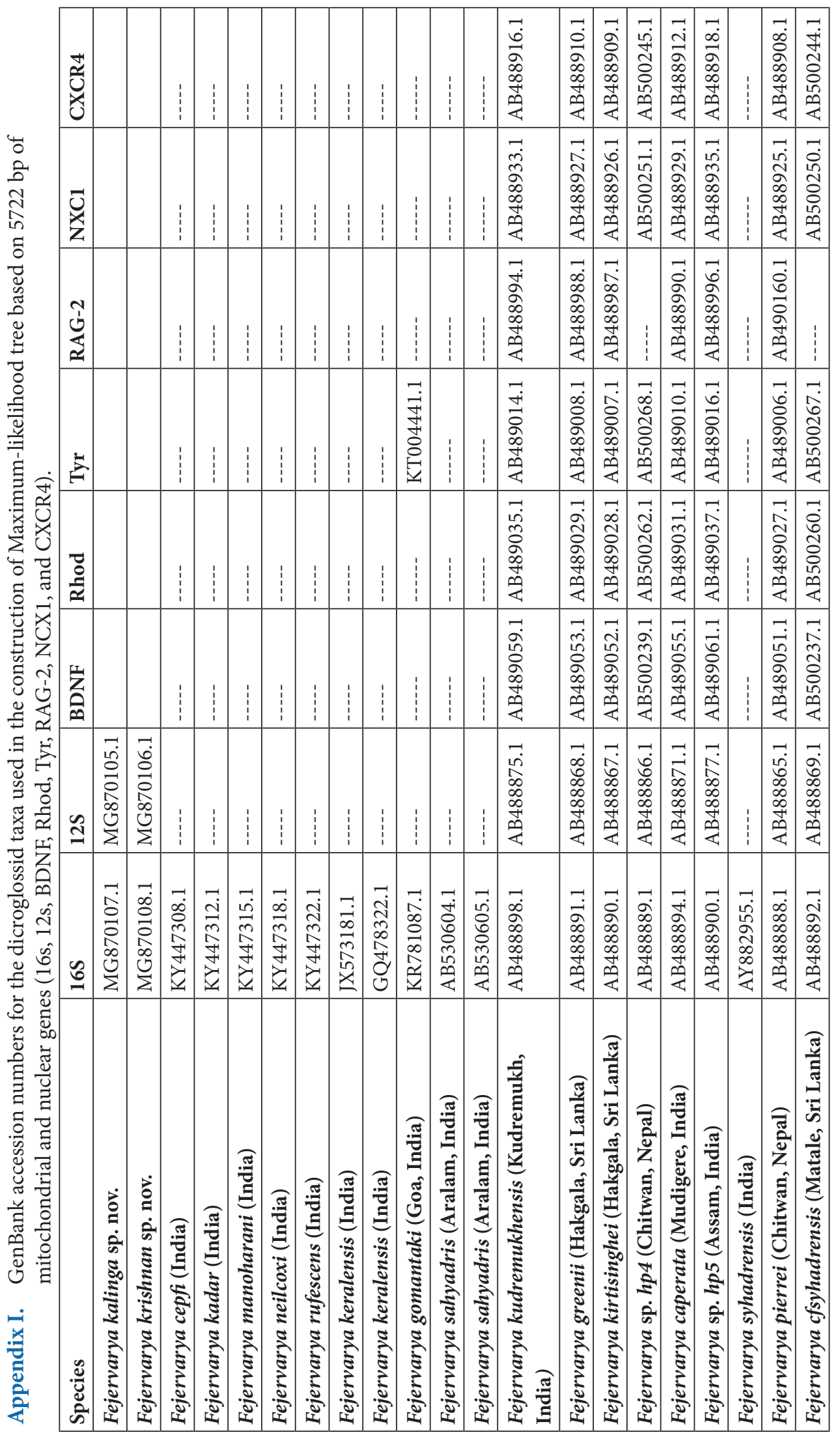




\begin{tabular}{|c|c|c|c|c|c|c|c|c|c|c|c|c|c|c|c|c|c|c|c|c|c|}
\hline 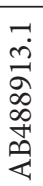 & 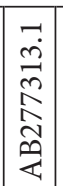 & 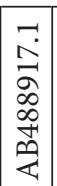 & 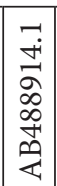 & 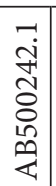 & 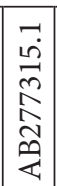 & 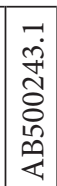 & 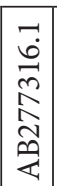 & $\begin{array}{l}\overrightarrow{1} \\
\stackrel{n}{n} \\
\stackrel{2}{N} \\
\stackrel{2}{q}\end{array}$ & 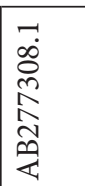 & 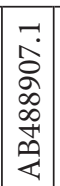 & 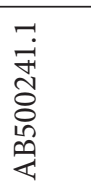 & 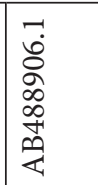 & 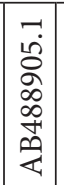 & 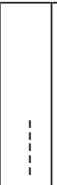 & & $\mid \begin{array}{c}-\overrightarrow{0} \\
\infty \\
\tilde{n} \\
\hat{N} \\
\hat{N} \\
\hat{z}\end{array}$ & & 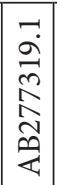 & \begin{tabular}{l}
$\vec{a}$ \\
$\vec{a}$ \\
$\infty$ \\
$\infty$ \\
+1 \\
\multirow{2}{*}{}
\end{tabular} & 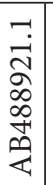 & \\
\hline 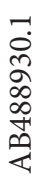 & & 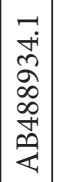 & 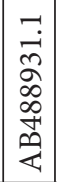 & 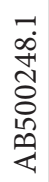 & 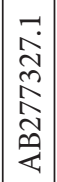 & 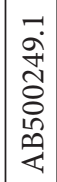 & 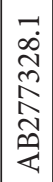 & 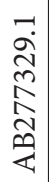 & 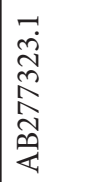 & 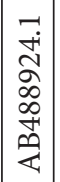 & 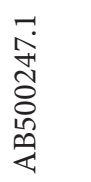 & 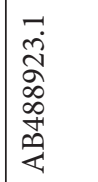 & 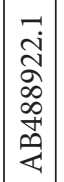 & & & 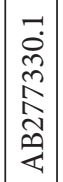 & 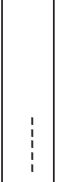 & 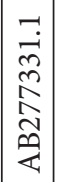 & $\begin{array}{l}7 \\
0 \\
2 \\
2 \\
0 \\
\infty \\
+1 \\
0 \\
2\end{array}$ & 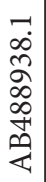 & 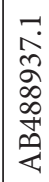 \\
\hline & & 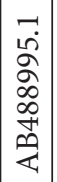 & 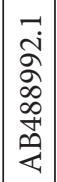 & 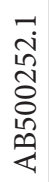 & 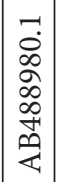 & 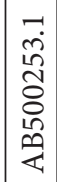 & $\begin{array}{l}\infty \\
\infty \\
\infty \\
\infty \\
\text { †े } \\
\text { के }\end{array}$ & 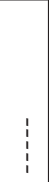 & 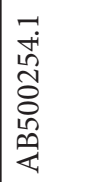 & 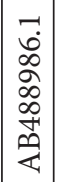 & i & 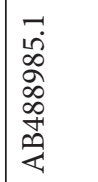 & 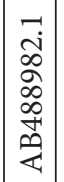 & & 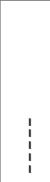 & 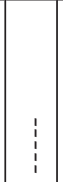 & 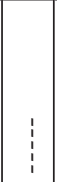 & 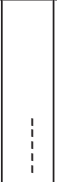 & 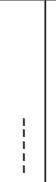 & & \\
\hline & 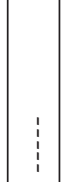 & 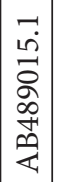 & 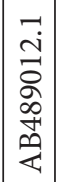 & 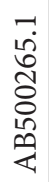 & 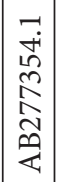 & 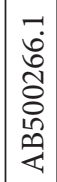 & 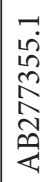 & 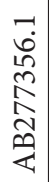 & $\begin{array}{l}\vdots \\
\vdots \\
\vdots\end{array}$ & 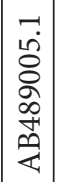 & 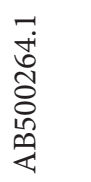 & 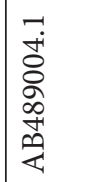 & 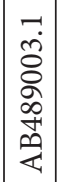 & & 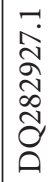 & 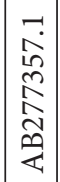 & & 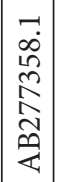 & 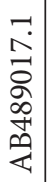 & $\begin{array}{l}\vec{a} \\
\vec{a} \\
\vec{a} \\
\text { के } \\
0 \\
0 \\
0 \\
0\end{array}$ & 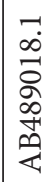 \\
\hline & & 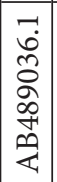 & 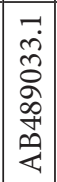 & 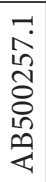 & 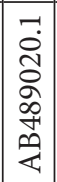 & 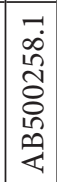 & 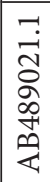 & 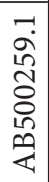 & 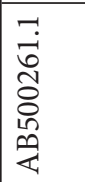 & 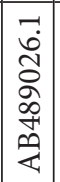 & 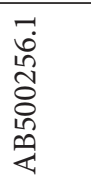 & 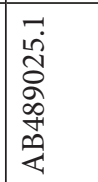 & 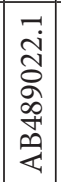 & & 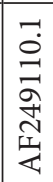 & 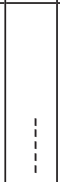 & 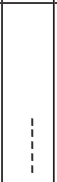 & 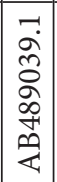 & 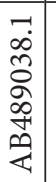 & 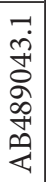 & 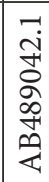 \\
\hline & & 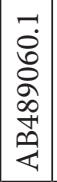 & $\vdots$ & 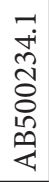 & 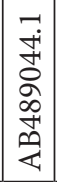 & 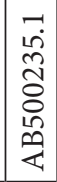 & 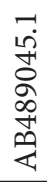 & 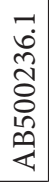 & 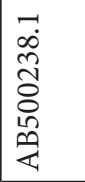 & 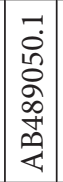 & 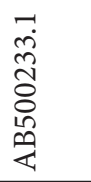 & 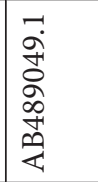 & 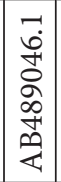 & 1 & & 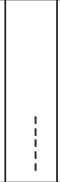 & $\begin{array}{c}\vdots \\
\vdots \\
1\end{array}$ & 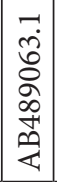 & 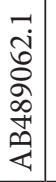 & 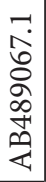 & 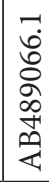 \\
\hline 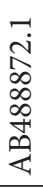 & 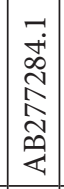 & 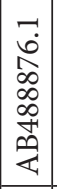 & $\mid \begin{array}{l}-1 \\
n \\
\infty \\
\infty \\
\infty \\
0+1 \\
0 \\
2\end{array}$ & 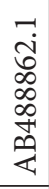 & 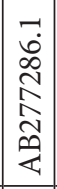 & 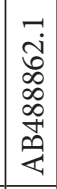 & 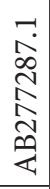 & 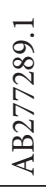 & & 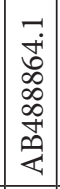 & 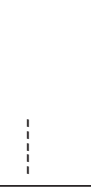 & $\mid \begin{array}{l}\overrightarrow{0} \\
0 \\
\infty \\
\infty \\
\infty \\
\infty \\
\infty \\
0\end{array}$ & $\mid \begin{array}{l}-1 \\
0 \\
\infty \\
\infty \\
\infty \\
\infty \\
\infty \\
0 \\
0 \\
\end{array}$ & \begin{tabular}{l}
-1 \\
0 \\
$\infty$ \\
$\infty$ \\
$\infty$ \\
$\infty$ \\
$\infty$ \\
$\infty$ \\
\hdashline
\end{tabular} & & 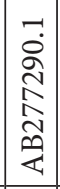 & 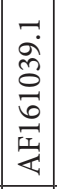 & 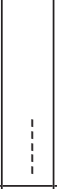 & & & \\
\hline 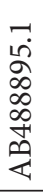 & $\mid \begin{array}{l}\overrightarrow{0} \\
\tilde{D} \\
\hat{\Lambda} \\
\hat{N} \\
\tilde{z}\end{array}$ & 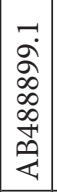 & 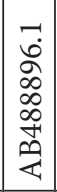 & 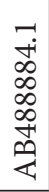 & 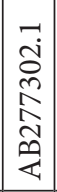 & 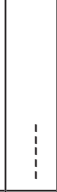 & 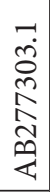 & 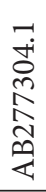 & & \begin{tabular}{l}
$\overrightarrow{1}$ \\
$\infty$ \\
$\infty$ \\
$\infty$ \\
$\infty$ \\
$\infty$ \\
+ \\
\multirow{2}{*}{}
\end{tabular} & 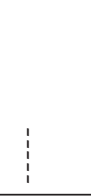 & \begin{tabular}{l}
$\vec{b}$ \\
$\infty$ \\
$\infty$ \\
$\infty$ \\
$\infty$ \\
$\infty$ \\
$\infty$ \\
\hdashline
\end{tabular} & 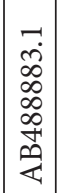 & 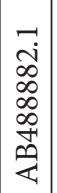 & & 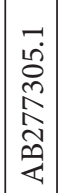 & 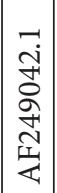 & 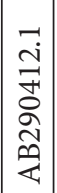 & 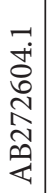 & & \\
\hline 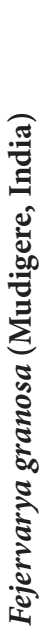 & 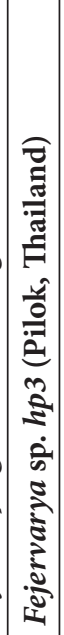 & 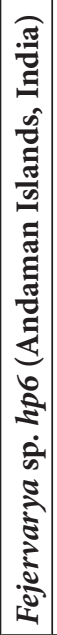 & 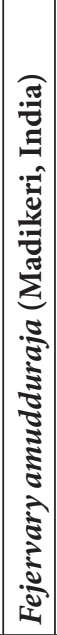 & 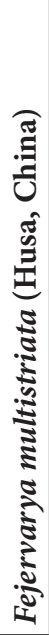 & 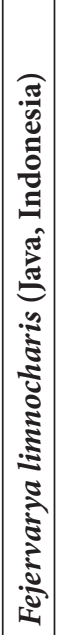 & 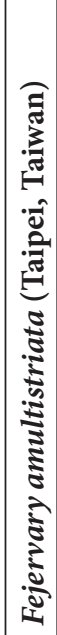 & 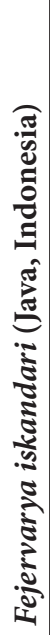 & 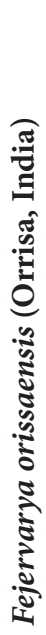 & 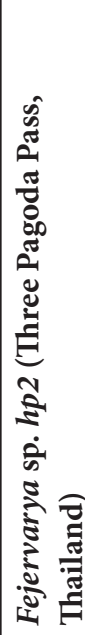 & 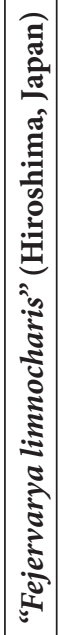 & 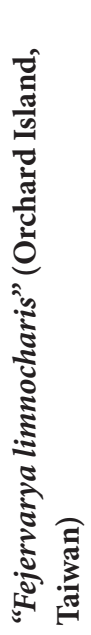 & 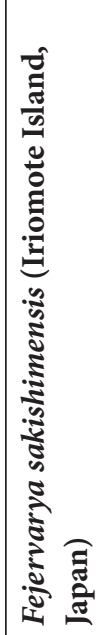 & 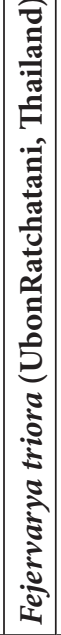 & 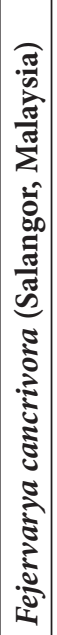 & 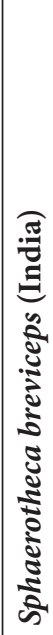 & 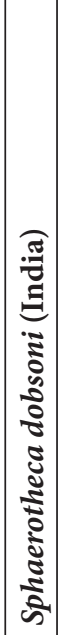 & 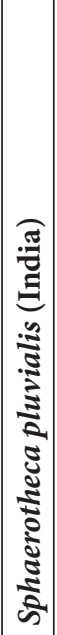 & 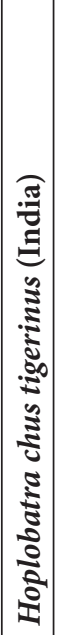 & 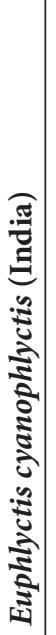 & 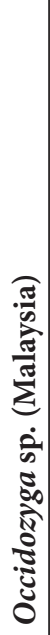 & 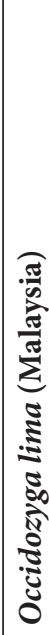 \\
\hline
\end{tabular}




\section{Appendix-II}

\begin{tabular}{|l|l|l|}
\hline Sl. No. & Localities & Registration number \\
\hline 1 & Mahendragiri, Gajapati, Odisha, India & ZSI/WRC/A/ 2018; 2022 \\
\hline 2 & Mahuia, Barbara RF, Khordha, Odisha, India & ZSI/WRC/A/2019; WII-7015 \\
\hline 3 & Rajanga, Hindol, Dhenkanal, Odisha, India & ZSI/WRC/A/2020; WII-7018, 7019 \\
\hline 4 & Sorada, Ganjam, Odisha, India & WII-7017 \\
\hline 5 & Potangi, Koraput, Odisha, India & WII-7013 \\
\hline 6 & Sileru, Visakhapatnam, Andhra Pradesh, India & ZSI/WRC/A/2021 \\
\hline
\end{tabular}

